\title{
Carryover effect of postpartum inflammatory diseases on developmental biology and fertility in lactating dairy cows
}

\author{
E. S. Ribeiro, ${ }^{*}{ }^{1}$ G. Gomes, ${ }^{*} \dagger$ L. F. Greco, ${ }^{*} \dagger$ R. L. A. Cerri, $\ddagger$ A. Vieira-Neto, ${ }^{*} \dagger$ P. L. J. Monteiro Jr., ${ }^{*} \dagger$ \\ F. S. Lima, ${ }^{*} \dagger^{2}$ R. S. Bisinotto, ${ }^{*} \dagger^{3}$ W. W. Thatcher, ${ }^{*} \dagger$ and J. E. P. Santos ${ }^{*} \dagger^{4}$ \\ *Department of Animal Sciences, University of Florida, Gainesville 32611 \\ †DH Barron Reproductive and Perinatal Biology Research Program, University of Florida, Gainesville 32611 \\ ¥Faculty of Land and Food Systems, University of British Columbia, Vancouver, BC V6T 1 Z4 Canada
}

\section{ABSTRACT}

The objective of this series of studies was to investigate the effects of inflammatory diseases occurring before breeding on the developmental biology and reproductive responses in dairy cows. Data from 5 studies were used to investigate different questions associating health status before breeding and reproductive responses. Health information for all studies was composed of the incidence of retained fetal membranes, metritis, mastitis, lameness, and respiratory and digestive problems from parturition until the day of breeding. Retained placenta and metritis were grouped as uterine disease (UTD). Mastitis, lameness, digestive and respiratory problems were grouped as nonuterine diseases (NUTD). Study 1 evaluated the effect of disease before artificial insemination (AI), anovulation before synchronization of the estrous cycle, and low body condition score at AI on pregnancy per AI, as well as their potential interactions or additive effects. Study 2 investigated the effect of site of inflammation (UTD vs. NUTD) and time of occurrence relative to preantral or antral stages of ovulatory follicle development, and the effect of UTD and NUTD on fertility responses of cows bred by AI or by embryo transfer. Study 3 evaluated the effect of disease on fertilization and embryonic development to the morula stage. Study 4 evaluated the effect of disease on preimplantation conceptus development as well as secretion of IFN- $\tau$ and transcriptome. Study 5 investigated the effect of diseases before AI on the transcript expression of interferon-stimulated genes in peripheral blood leukocytes during peri-implantation stages of conceptus development after first

Received September 1, 2015.

Accepted November 5, 2015.

${ }^{1}$ Current address: Department of Animal Biosciences, University of Guelph, Guelph, ON, Canada N1G 2W1.

${ }^{2}$ Current address: Department of Veterinary Clinical Medicine, University of Illinois Urbana-Champaign, Urbana 61802.

${ }^{3}$ Current address: Department of Veterinary Population Medicine, University of Minnesota, St. Paul 55108.

${ }^{4}$ Corresponding author: Jepsantos@ufl.edu
AI postpartum. Altogether, these studies demonstrated that inflammatory disease before breeding reduced fertilization of oocytes and development to morula, and impaired early conceptus development to elongation stages and secretion of IFN- $\tau$ in the uterine lumen. Diseases caused inflammation-like changes in transcriptome of conceptus cells, increased risk of pregnancy loss, and reduced pregnancy or calving per breeding. Moreover, the effects on reproduction were independent of cyclic status before synchronization of the estrous cycle and body condition score at breeding, which all had additive negative effects on fertility of dairy cows. Occurrence of disease at preantral or at antral stages of ovulatory follicle development had similar detrimental effects on pregnancy results. The carryover effects of diseases on developmental biology might last longer than 4 mo. Reduced oocyte competence is a likely reason for carryover effects of diseases on developmental biology, but impaired uterine environment was also shown to be involved.

Key words: dairy cow, disease, embryo, fertility

\section{INTRODUCTION}

Transition from the nonlactating pregnant state to nonpregnant lactating state requires a dairy cow to drastically adjust her metabolism so that nutrients can be partitioned to support milk synthesis, a process referred to as homeorhesis (Bauman and Currie, 1980). A sharp increase in nutrient requirements generally occurs at the onset of lactation, when feed intake is usually depressed, which causes extensive mobilization of body tissues, particularly body fat, but also AA, minerals, and vitamins (Santos et al., 2010). Despite orchestrated homeostatic controls and homeorhetic adjustments to cope with the changes in metabolism caused by milk production, 40 to $70 \%$ of dairy cows across different levels of milk production, breeds, and management systems develop metabolic or infectious diseases in the first months of lactation (Santos et al., 2010; Ribeiro et al., 2013). These health problems not 
only cause reductions in milk production and increases in production costs, but also reduce reproductive performance of dairy cows (Santos et al., 2010; Ribeiro et al., 2013), which consequently impairs sustainability of dairy herds (Ribeiro et al., 2012).

Reproductive efficiency in dairy herds depends on adequate submission of lactating cows to breeding in a timely manner with adequate pregnancy per AI (P/ AI). The development of programs that efficiently synchronize the estrous cycle and ovulation of cattle and the current increase of their usage for management of reproduction of dairy herds have successfully improved submission to insemination (Bisinotto et al., 2014); nonetheless, the resulting $\mathrm{P} / \mathrm{AI}$ still is suboptimal. Early embryonic mortality in lactating dairy cows is substantial (Santos et al., 2004; Diskin et al., 2006) and likely the main cause of inadequate pregnancy results. Interestingly, early pregnancy losses do not seem to occur randomly, but have predisposing factors. Inflammatory diseases occurring before breeding (Santos et al. 2010; Ribeiro et al., 2013), anovulation before synchronization of the estrous cycle (Santos et al., 2004), and low BCS at AI (Santos et al., 2009) are factors that have been implicated with reduced P/AI and increased early and late embryonic mortality. Diseases have great significance for reproduction in dairy herds because of the high prevalence and because of the association with other fertility stressors such as anovulation and low BCS (Santos et al., 2009; Santos et al., 2010; Ribeiro et al., 2013).

The biological mechanisms by which postpartum diseases impair reproduction, however, are not clearly understood. Most studies are of an epidemiological nature and the overwhelming majority associate negative effects of diseases during early lactation with reduced $\mathrm{P} / \mathrm{AI}$ or extended intervals to pregnancy. Important questions remain on how diseases affect developmental biology, whether diseases that are of uterine or nonuterine origin affect fertility differently, the timing of disease occurrence relative to breeding, and the role of other associated risk factors that depress fertility, such as anovulation and low BCS, that are more prevalent in cows that suffer disease. Altogether, the biology that underlies subfertility attributed to diseases remains elusive and deserves investigation.

The objectives of this series of studies were to characterize the effect of inflammatory diseases before breeding on developmental biology and reproduction in dairy cows. To accomplish the objectives, we attempted to (1) isolate the effects of diseases, anovulation at the initiation of synchronization program, and low BCS at breeding and their potential interactions or additive effects; $(2)$ isolate the effects of uterine and nonuterine diseases and their potential interactions or additive effects; (3) evaluate the importance of the time when the disease occurs relative to breeding regarding effects on reproduction, as well as the contribution of the uterine environment during posthatching stages of embryo development on the etiology of subfertility caused by diseases before breeding; (4) evaluate the effect of disease on fertilization and embryonic development to the morula stage and the effect of disease on preimplantation conceptus development as well as secretion of IFN- $\tau$ and transcriptome; and (5) evaluate the effect of diseases before AI on the transcript expression of interferon-stimulated genes in peripheral blood leukocytes during peri-implantation stages of conceptus development.

\section{MATERIALS AND METHODS}

\section{Study 1: Disease, Anovulation, and Low BCS and Effects on Fertility Responses}

The objective of study 1 was to evaluate the effect of inflammatory diseases before AI, anovulation before synchronization of the estrous cycle, and low BCS at $\mathrm{AI}$ on $\mathrm{P} / \mathrm{AI}$ for the first AI postpartum, as well as their potential interaction or additive effects. The 3 traits have often been implicated individually with reduced fertility in dairy cows, and only a few studies have investigated the relationship or dependence among them (Hernandez et al., 2012; Vieira-Neto et al., 2014). For that, information regarding health of cows from parturition to first AI, estrous cyclicity before estrous cycle synchronization, $\mathrm{BCS}$ at $\mathrm{AI}$, and $\mathrm{P} / \mathrm{AI}$ at first $\mathrm{AI}$ postpartum was evaluated from 2,190 cows enrolled in 5 controlled experiments: 4 conducted in Florida (Lima et al., 2014; Ribeiro et al., 2013; 2015; Wang et al., 2013) and 1 in California (Rutigliano et al., 2008).

Retention of fetal membranes was recorded on the first day postpartum and cows were evaluated for the incidence of metritis by transrectal palpation and examination of uterine discharge on the first $10 \mathrm{~d}$ postpartum. Incidence of mastitis, lameness, and digestive and respiratory problems were evaluated from parturition until first AI postpartum. At every milking, all cows were examined for signs of clinical mastitis by the herd personnel immediately before milking. Clinical mastitis was characterized by the presence of abnormal milk or by signs of inflammation in one or more quarters. Digestive problems were characterized by diarrhea, bloat, or displacement of abomasum. Respiratory problems were characterized by increased respiratory frequency associated with fever and presence of increased lung sounds at auscultation.

Estrous cyclicity before synchronization of the estrous cycle was determined either by progesterone con- 
centrations in plasma or ultrasonographic examination of the ovaries, both performed twice, 12 to $14 \mathrm{~d}$ apart. Progesterone concentrations $\geq 1.0 \mathrm{ng} / \mathrm{mL}$ or presence of a corpus luteum in at least 1 of the 2 examinations characterized an estrous cyclic cow, whereas the absence of these criteria in the 2 examinations characterized an anovular cow. The body condition was scored at AI using a 1 (emaciated) to 5 (obese) scale with 0.25 -unit increments according to Ferguson et al. (1994). Cows with BCS $<3.0$ at AI were classified as low BCS and the remaining as moderate BCS. Pregnancy was diagnosed by ultrasonography examination of the uterus on d 32 (28 to 35 across all studies) and 65 (63 to 68 across all studies) after AI. Pregnancy loss between d 32 and 65 after AI was determined by the proportion of cows diagnosed pregnant on d 32 but nonpregnant on d 65 .

Statistical models to predict fertility responses included 2 out of the 3 binary categories: (1) incidence of diseases before AI (yes or no), (2) anovulation before synchronization of the estrous cycle (yes or no), and (3) low BCS at AI (yes or no). In addition, the models included the interaction term between the 2 dependent variables and the covariates parity (primiparous or multiparous), DIM at AI (continuous variable), and study (1 to 5$)$.

\section{Study 2: Effect of Site of Inflammation and Timing of Diagnosis}

Study 2 consisted of a detailed compilation of health and reproductive information from all calvings occurring in $2012(\mathrm{n}=5,085)$ from a confinement dairy farm in north-central Florida. Health data included the incidence and the date of diagnosis of retained fetal membranes, metritis, mastitis, lameness, and respiratory and digestive problems, which were diagnosed as described above. The window of disease occurrence evaluated, however, was from calving until $42 \mathrm{~d}$ after the first breeding postpartum. Retained placenta and metritis were grouped as uterine disease (UTD). Mastitis, lameness, and digestive and respiratory problems were grouped as nonuterine diseases (NUTD). Only first breeding was included in the analyses. Cows received the first breeding either through AI or embryo transfer (ET). Pregnancies per AI or ET were evaluated on d 45 and 90 after breeding, and to term, to calculate pregnancy on d 45, 90, and at the end of gestation, and pregnancy losses throughout gestation. Our rationale was to compare the effect of type of disease (UTD vs. NUTD) in cows receiving AI or ET and evaluate whether ET can bypass some of the detrimental effect of disease on pregnancy typically observed with AI. By evaluating AI and ET, inferences could be made on changes in fertility attributed to the posthatching stages of embryo development and not to oocyte quality, fertilization, and development to blastocyst stage.

The first objective was to determine if UTD or NUTD had similar or distinct effects on fertility of dairy cows and whether they interact or have additive effects. This was accomplished by modeling the fertility responses with the effects of UTD, NUTD, and the interaction between UTD and NUTD. A contrast of interest was used to evaluate the additive effect UTD and NUTD combined compared with either UTD or NUTD alone. The models also included the effects of parity (primiparous or multiparous), month of breeding according to the Julian calendar (1 to 12), synchronization of estrous cycle (synchronized or bred after estrus), type of breeding (AI or ET), and DIM at breeding. Type of embryo used on ET (fresh in vitro-produced embryo, frozen in vitro-produced embryo, or frozen in vivo-produced embryo from superstimulated donor cows) and sire used on AI were combined in one variable, which was also used in the statistical models nested within breeding type.

The second objective was to evaluate the timing of NUTD occurrence relative to breeding and its relationship with fertility responses. Differences in days postpartum from the day of disease diagnosis and the day of breeding were calculated and cows were classified as having or not suffered from diseases during preantral stages of ovulatory follicle development (preantral: diagnosis up to $43 \mathrm{~d}$ before breeding), antral stages of ovulatory follicle development (antral: diagnosis between $42 \mathrm{~d}$ before to the day of breeding; Lussier et al., 1987) and during early stages of conceptus development (postbreeding: from 1 to $42 \mathrm{~d}$ after breeding). Three statistical analyses were performed. First, the effect of disease (yes or no) on fertility responses was evaluated for the preantral, antral, or early postbreeding period. The second analysis modeled the effect of interval from the last disease diagnosis and day of breeding as a continuous predictor of the reproductive responses of interest. For the third analysis, the interval between the last diagnosis of disease and breeding was categorized as preantral, antral, or postbreeding. Cows that did not suffer from NUTD were used as controls in analysis 3 . In all 3 models, the same covariates previously described (parity, month of breeding, DIM at breeding, synchronization, type of breeding, and embryo type or sire nested within type of breeding) were also included in the statistical models.

The third objective was to evaluate the effect of UTD and NUTD on fertility responses of cows bred by AI or ET. For this analysis, the window of disease occurrence was shortened until the day of breeding to evaluate the carryover effect of disease before AI or ET on subsequent fertility. The same covariates described 
above were used in addition with the interaction terms between disease classification and type of breeding to evaluate if diseases have similar or distinct effect in cows receiving AI or ET.

\section{Study 3: Effect of Disease on Development to the Morula Stage}

Study 3 was a compilation of 4 experiments (Cerri et al., 2009a,b,c, 2011) evaluating the embryonic development to the morula stage in lactating dairy cows receiving the first AI postpartum. The objective was to evaluate the effect of diseases before AI on the early development of bovine embryos. For that, incidence of diseases before AI were collected as described above for a total of 635 cows subjected to estrous cycle synchronization and inseminated between 46 and $60 \mathrm{~d}$ postpartum. Only cows that ovulated within $36 \mathrm{~h}$ of AI and had low $(<1.0 \mathrm{ng} / \mathrm{mL})$ progesterone on the day of AI, but high $(\geq 1.0 \mathrm{ng} / \mathrm{mL})$ progesterone on the day of uterine flushing were used in the analysis.

On d 5 or 6 after insemination, the uterine horn ipsilateral to the corpus luteum was flushed transcervically using a Foley catheter. Recovered ova-embryos were classified from 1 to 5 based on cleavage and grade quality (IETS, 1998), where 1 = excellent or good quality, $2=$ fair quality, $3=$ poor quality, $4=$ degenerated, and $5=$ noncleaved. Embryos graded 1 and 2 were considered high-quality embryos and those graded 1 to 3 as live embryos. The responses evaluated were proportion of cleaved embryos from all recovered ovaembryos, and the proportion of high quality or that of live embryos among all ova-embryos or among only embryos. The statistical models included the effects of disease category, experiment, parity, and BCS at AI, and the random effect of predesigned treatment nested within experiment.

\section{Study 4: Effect of Disease on Conceptus Development and Transcriptome}

Study 4 comprised data from 3 experiments (Greco et al., 2012; Gomes et al., 2013; Ribeiro, 2015) evaluating preimplantation conceptus development at the onset of elongation in lactating dairy cows receiving the first AI postpartum. The objective was to evaluate the effect of diseases before AI on the conceptus development, length, and secretion of IFN- $\tau$, and the effect of NUTD on the transcriptome of conceptus cells. For that, health information regarding incidence of diseases before AI was collected as previously described for a total of 148 cows that had estrous cycle synchronized and were inseminated for the first time postpartum between 46 and $65 \mathrm{~d}$ postpartum. On d 15 or 16 after AI, the uterine horn ipsilateral to the corpus luteum was flushed transcervically. The first $20 \mathrm{~mL}$ of PBS with $0.1 \%$ of polyvinyl alcohol infused was recovered, examined in a petri dish under a stereoscope for presence of the conceptus, and then processed for later analyses. Up to 5 additional flushings were performed if no conceptus tissue was recovered.

The recovered conceptuses were washed in fresh drops of PBS with $0.1 \%$ of polyvinyl alcohol and, after measuring the length, were snap-frozen in liquid $\mathrm{N}_{2}$ and stored at $-80^{\circ} \mathrm{C}$ until nucleic acid extraction. The uterine fluid retrieved during the first flushing was placed in conical tubes in ice and later centrifuged at $2,000 \times g$ at $4^{\circ} \mathrm{C}$ for $15 \mathrm{~min}$. The supernatant was collected, homogenized, aliquoted, and stored at $-80^{\circ} \mathrm{C}$ for later analysis of IFN- $\tau$ concentration. The antiviral assay for IFN- $\tau$ described by Rodina et al. (2009) was used. Blood was sampled on d 0, 7, and 15 relative to AI by puncture of the coccygeal vessels into evacuated tubes containing $\mathrm{K}_{2}$ EDTA (Becton, Dickinson, and Company, Franklin Lakes, NJ). Samples were placed immediately in ice and later centrifuged at 2,000 $\times$ $g$ at $4^{\circ} \mathrm{C}$ for $15 \mathrm{~min}$ for plasma separation. Aliquots of plasma were frozen at $-25^{\circ} \mathrm{C}$ for later analyses of progesterone concentrations by RIA.

Responses evaluated included the proportion of cows pregnant on d 15 based on detection of IFN- $\tau$ in the uterine fluid, length of the conceptus recovered intact, concentration of IFN- $\tau$ in the uterine fluid of pregnant cows, and progesterone concentration in plasma after AI. The statistical models included the effects of disease category, study, and the effect of predesigned treatment nested within study. For the analysis of concentration of progesterone in plasma, the statistical model also included the fixed effects of day of sampling, the interaction between disease and day of sampling, and the random effect of cow nested within disease category.

Conceptuses were subjected to transcriptome analysis to investigate the carryover effects of NUTD on the biology of conceptus cells during elongation. A total of 22 conceptuses, 12 from d 15 and 10 from d 16 after AI, were used. Half of the selected conceptuses on each day were recovered from cows affected by NUTD before AI. Each conceptus from cows with NUTD was matched with a conceptus of similar length but from a cow not affected by NUTD.

Total mRNA from conceptus cells was extracted using the AllPrep DNA/RNA kit (Qiagen, Germantown, MD) according to manufacturer instructions. Transcriptome analysis was performed using the GeneChip Bovine Genome Array (Affymetrix, Santa Clara, CA) at the Interdisciplinary Center for Biotechnology Research 
Microarray Core at University of Florida, Gainesville. All microarray sample preparation used the GeneChip 3' IVT Express kit (Affymetrix), and reactions were carried out following the manufacturer's protocols as described by Ribeiro (2015).

\section{Study 5: Effect of Disease on Blood Immune Cell Responses to IFN-T}

The objective of study 5 was to evaluate the effect of diseases before AI on the transcript expression of interferon-stimulated genes (ISG) in peripheral blood leukocytes (PBL) during peri-implantation stages of conceptus development. Data consisted of transcript expression of the genes ISG15 and receptor (chemosensory) transporter protein 4 (RTP4) in PBL sampled on d 19 after first AI postpartum from 231 cows in 2 experiments (Monteiro et al., 2014; Ribeiro et al., 2014). Health data compilation was performed as previously described. The PBL were isolated from blood according to Ribeiro et al. (2014). Extraction of RNA was conducted according to the manufacturer's recommendations for the RNA-extraction kit (PureLink RNA Mini Kit; Invitrogen, Carlsbad, CA). Transcript expression was evaluated by quantitative real-time reverse transcription-quantitative PCR (ABI 7500 Sequence Detector; Applied Biosystems Inc., Foster City, CA). Two reference genes, $\beta$-actin $(A C T B)$ and ribosomal protein L19 (RPL19), were investigated to normalize gene expression for ISG.

Data are presented using the comparative method described by Livak and Schmittgen (2001) and using cows that did not suffer from diseases before AI and were diagnosed nonpregnant on d 62 after AI as the reference group for comparison. Relative expression values were obtained by raising the PCR amplification efficiency $(\mathrm{E}=2)$ to the power of the delta-delta threshold cycle obtained from the delta threshold cycle (CT) least squares means differences of pairwise comparisons between reference and target groups (Yuan et al., 2006). Confidence intervals for graphical representations of relative expression were generated from the lower and upper 95\% confidence intervals obtained for $\Delta \mathrm{CT}$ least squares means differences (Yuan et al. 2006).

The $\Delta \mathrm{CT}$ values subjected to statistical analysis were obtained after normalization of $\mathrm{CT}$ values from target genes using the geometric mean of $\mathrm{CT}$ values from the 2 reference genes (Vandesompele et al., 2002). The statistical models included the effect of disease category, the effect of pregnancy status on d 32 or 64 after $\mathrm{AI}$, the interaction between disease and pregnancy, the covariates study number, parity and BCS at AI, and the effect of preassigned treatment nested within study.

\section{Statistical Analyses}

Statistical analyses were performed using the GLIMMIX procedure of SAS version 9.3 (SAS/STAT, SAS Institute Inc., Cary, NC) and fitting adequate data distribution. Continuous variables were analyzed by ANOVA and binary variables were analyzed by logistic regression. The statistical models were previously described in the materials and methods. Differences with $P \leq 0.05$ were considered as significant and $0.05<P \leq$ 0.15 were considered as a tendency.

Microarray data were analyzed using Bioconductor packages (www.bioconductor.org) in $\mathrm{R}$ version 3.1.1 (www.r-project.org). Analysis from d 15 and 16 were performed separately. Data were preprocessed using Gene Chip Robust Multi-Array function (Wu et al., 2004). Limma package (Smyth, 2005) was then used to fit a linear model and to adjust variances by empirical Bayes adjustment according to Smyth (2004). Moderate $t$-test was performed for pairwise comparisons between cows without NUTD and those that suffered from NUTD, and $P$-values were adjusted for multiple testing using the Benjamini and Hochberg false discovery rate (Benjamini and Hochberg, 1995). Adjustment for multiple group comparisons was performed by using the Global method within the decideTests function in Limma. Differently expressed genes were considered when adjusted $P<0.05$ and fold change was $\geq 1.5$. Networks, functional and causal analyses were performed using Qiagen Ingenuity Pathway Analysis software (Qiagen, Redwood City, CA, www.qiagen. com/ingenuity). Emphasis was given to canonical pathways, predicted upstream regulators and predicted downstream effects with a Z-score $(\boldsymbol{Z} \boldsymbol{S})<-2.0$ or $>2.0$ and overlap $P$-value $(\boldsymbol{O P})<0.05$. Information regarding algorithms and statistical methods used in causal analysis of Ingenuity Pathway Analysis were described by Krämer et al. (2014).

\section{RESULTS}

\section{Study 1: Disease, Anovulation, and Low BCS and Fertility Responses Effects}

Of the 2,190 cows evaluated, 42.1, 22.2, and $52.9 \%$ suffered from clinical diseases before AI, were anovular before synchronization of the estrous cycle, and had low BCS at AI, respectively. Disease increased $(P<0.05)$ the proportions of anovular (18.9 vs. $26.6 \%)$ and low BCS (49.3 vs. $58.5 \%$ ) cows. The P/AI were 45.7 and $40.1 \%$ on d 32 and 65 after AI, respectively, and $10.5 \%$ of the pregnant cows on d 32 lost pregnancy by d 65 . Diseases before AI, anovulation before synchronization of the estrous cycle and low BCS at AI affected nega- 
tively $\mathrm{P} / \mathrm{AI}$ on $\mathrm{d} 32$ (Figure 1 ). Cows diagnosed with disease before AI had reduced $(P<0.01) \mathrm{P} / \mathrm{AI}$ on $\mathrm{d} 32$ compared with those that did not suffer disease (31.4 vs. 40.3\%). Anovular cows had reduced $(P<0.01) \mathrm{P} /$ AI on d 32 compared with estrous cyclic cows (27.2 vs. $45.2 \%)$. Cows with low BCS had reduced $(P<0.01)$ $\mathrm{P} / \mathrm{AI}$ on $\mathrm{d} 32$ compared with those of moderate BCS (36.4 vs. $49.2 \%)$. No interaction was observed between clinical disease and anovulation (Figure 1A) or between clinical disease and low BCS at AI (Figure 1B), thus suggesting independent effects on fertility. In addition, additive negative effects of clinical disease and anovulation were observed (Figure 1A), as well as clinical disease and low BCS (Figure 1B) on P/AI. Similar to d 32 , cows diagnosed with disease before AI had reduced $(P<0.01) \mathrm{P} /$ AI on d 65 compared with those that did not suffer disease (27.2 vs. $36.9 \%)$; anovular cows had reduced $(P<0.01) \mathrm{P} / \mathrm{AI}$ on d 65 compared with estrous cyclic cows (24.6 vs. $40.0 \%$ ); and cows with low BCS had reduced $(P<0.01) \mathrm{P} / \mathrm{AI}$ on d 65 compared with those of moderate BCS (32.3 vs. 42.4\%). No interaction was observed between clinical disease and anovulation $(P=0.45)$ or between clinical disease and low BCS at AI $(P=0.61)$. In addition, additive negative effects of clinical disease and anovulation were noted $(P<0.01)$, as well as clinical disease and low BCS $(P<0.01)$ on $\mathrm{P} / \mathrm{AI}$ on d 65. Disease, estrous cyclicity, or BCS, and the interactions between disease and estrous cyclicity or BCS did not influence pregnancy loss between 32 and $65 \mathrm{~d}$ of gestation.

\section{Study 2: Site of Inflammation and Timing of Diagnosis}

Of the 5,085 cows that calved in the year of 2012, $1,994(39.2 \%)$ suffered at least one clinical disease from
A
$\square$ No disease and cyclic
$\square$ No disease and anovular
$\square$ Disease and cyclic
- Disease and anovular

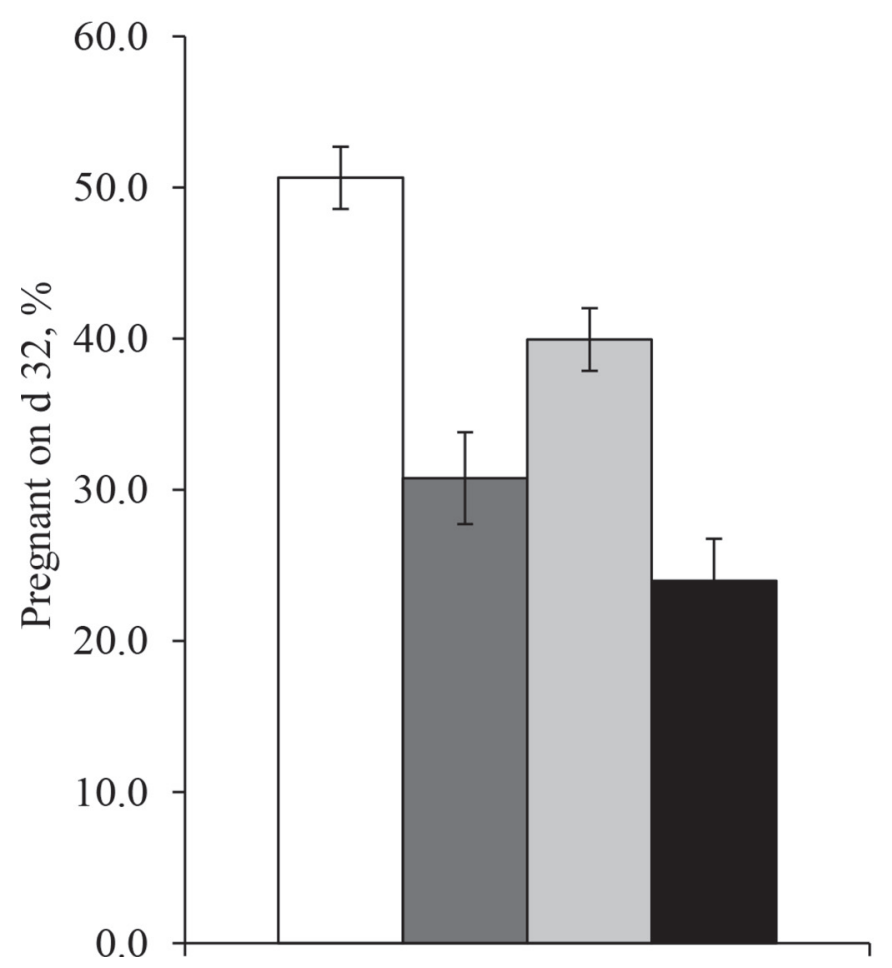

B
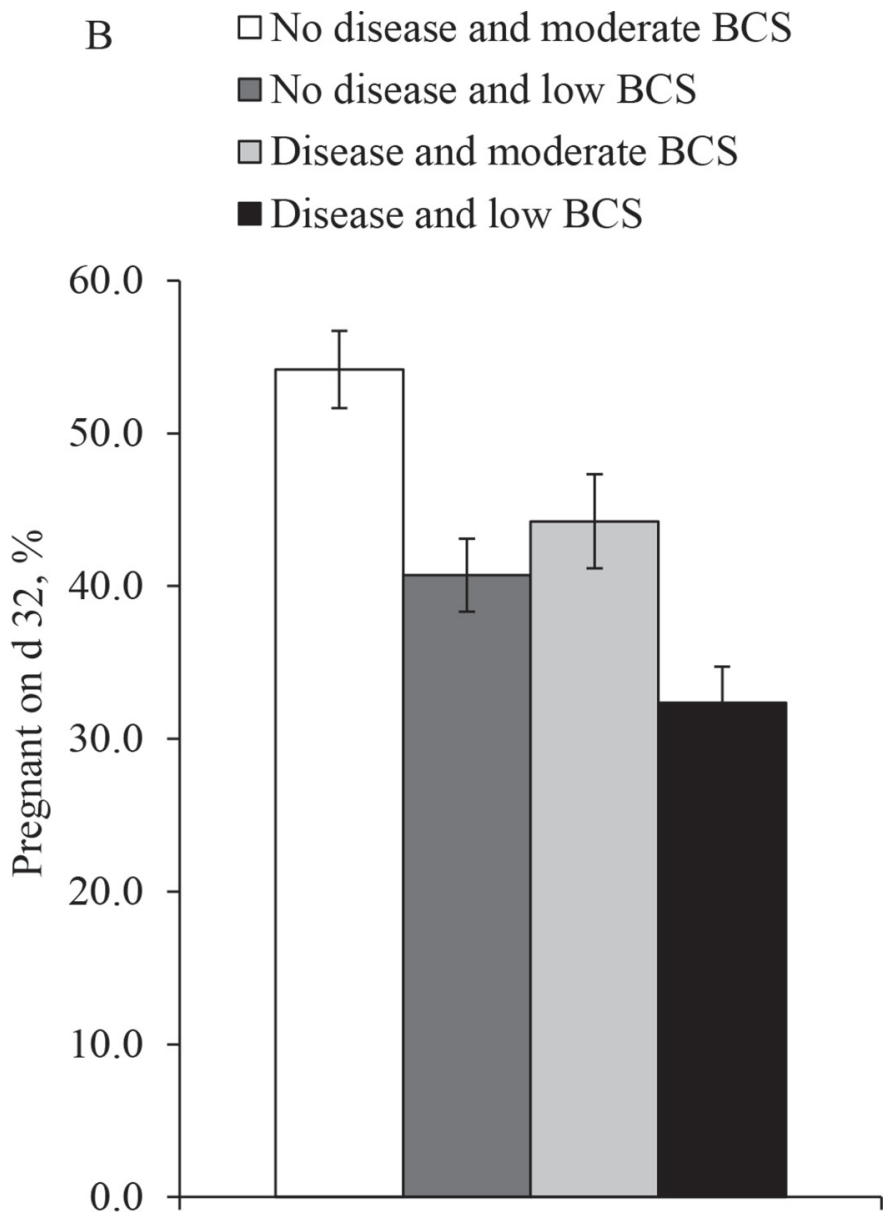

Figure 1. Pregnancy per AI on d 32 after AI according to incidence of diseases before AI and anovulation before synchronization of the estrous cycle (A) or low BCS at AI (B) in study 1 . For panel A, effect of disease $(P<0.01)$, anovulation $(P<0.01)$, interaction between disease and anovulation $(P=0.70)$, and the additive effect of disease and anovulation $(P<0.01)$ were noted. For panel $\mathrm{B}$, effect of disease $(P<0.01)$, BCS $(P<0.01)$, interaction between and BCS $(P=0.86)$, and the additive effect of disease and low BCS $(P<0.01)$ were noted. Error bars represent the SEM. 
calving until the pregnancy diagnosis following the first AI. The incidences of retained fetal membranes, metritis, mastitis, digestive problems, pneumonia, and lameness were, respectively, 13.2, 18.1, 10.6, 8.1, 1.3, and $6.2 \%$. Retained placenta and metritis, which combined to characterize UTD, affected $22.1 \%$ of the cows, whereas the other diseases that characterized NUTD affected $23.0 \%$ of the cows. Uterine diseases were diagnosed during the first 2 wk postpartum, whereas the mean $( \pm \mathrm{SD})$ and median DIM at the diagnosis of NUTD were $36.2 \pm 37.4$ and 19.0, respectively (Figure 2 ). In fact, $53.3 \%$ of the first diagnosis of NUTD occurred in the first $3 \mathrm{wk}$ postpartum and affected $12.3 \%$ of the cows. Combined with UTD, $30.6 \%$ of the cows were affected by clinical diseases in on the first $3 \mathrm{wk}$ postpartum, which represent $78.1 \%$ of the first diagnosis of clinical disease postpartum.

A total of $340(6.7 \%)$ cows either died or were sold before first breeding, and another $51(1.0 \%)$ cows left the herd before the pregnancy diagnosis following the first breeding. In addition, 488 (9.6\%) cows were kept in the herd but excluded from the reproductive program before the end of voluntary waiting period of 56 DIM and were eventually culled from the herd. Thus, $879(17.3 \%)$ cows did not contribute with reproduction data. Disease increased $(P<0.01)$ the proportion of cows that either left the herd or were removed from the reproductive program (24.1 vs. $12.9 \%)$, and this was true for both UTD (21.2 vs. 16.2\%) and NUTD (29.4 vs. $13.7 \%)$.

The mean $( \pm \mathrm{SD})$ and median days to first breeding were $81.3 \pm 13.1$ and 77.0, respectively. Disease nega- tively affected $(P<0.01)$ pregnancy per breeding on $\mathrm{d}$ 45 (39.8 vs. $32.9 \%)$ or 90 (35.5 vs. $27.2 \%)$ and calving per breeding (33.2 vs. $23.3 \%)$, and increased $(P<0.01)$ the incidence of pregnancy loss from gestation d 45 to term (13.6 vs. $23.3 \%)$. These findings were observed in both UTD and NUTD. In fact, UTD and NUTD had an additive effect reducing $(P=0.02)$ calving per breeding and increasing $(P=0.05)$ pregnancy loss (Figure 3$)$.

Diagnosis of NUTD at the estimated preantral (Figure 4A) and antral stages of ovulatory follicle development (Figure 4B) and at early postbreeding (Figure $4 \mathrm{C})$ reduced pregnancy and calving per breeding and increased pregnancy loss. Similar results were obtained when only the last NUTD occurrence was considered (Figure 5). The period at which the last NUTD occurred did not change the effect of NUTD on fertility compared with cows without NUTD (Figure 5). In agreement with this finding, no association $(P>0.38)$ was observed between the interval from the diagnosis of the last NUTD to breeding used as a continuous variable and fertility responses.

The negative effect of disease before breeding on fertility responses was observed in cows receiving AI or ET (Figure 6). In fact, cows diagnosed with disease had depressed fertility irrespective of type of breeding, suggesting that ET does not bypass the negative effect of disease on maintenance of pregnancy in dairy cows (Figure 6A). Analyses of the effect of UTD (Figure 6B) and those of NUTD (Figure 6C) also showed a reduction in pregnancy per breeding evaluated on d 45 or at calving and an increase in pregnancy loss in cows receiving AI or ET.

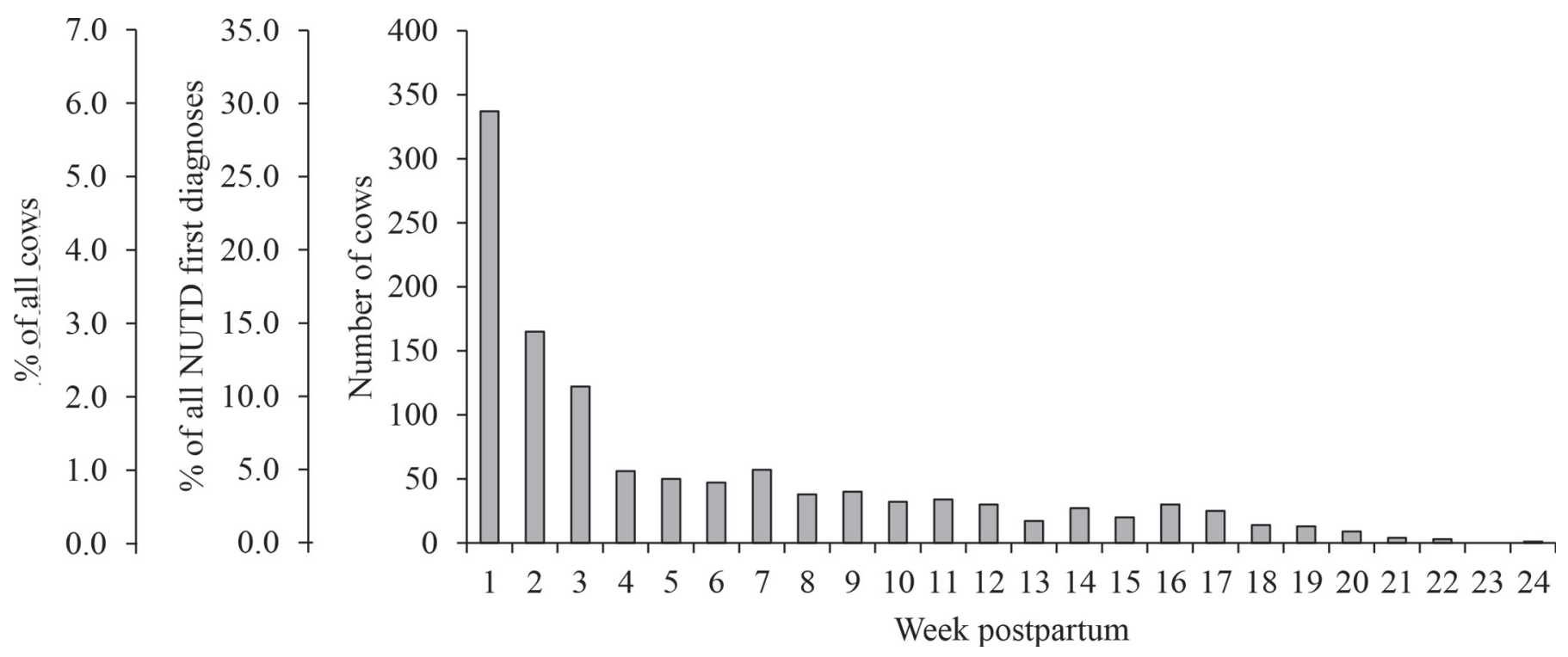

Figure 2. Frequency distribution according to the first diagnosis of nonuterine disease (NUTD) in study 2. 


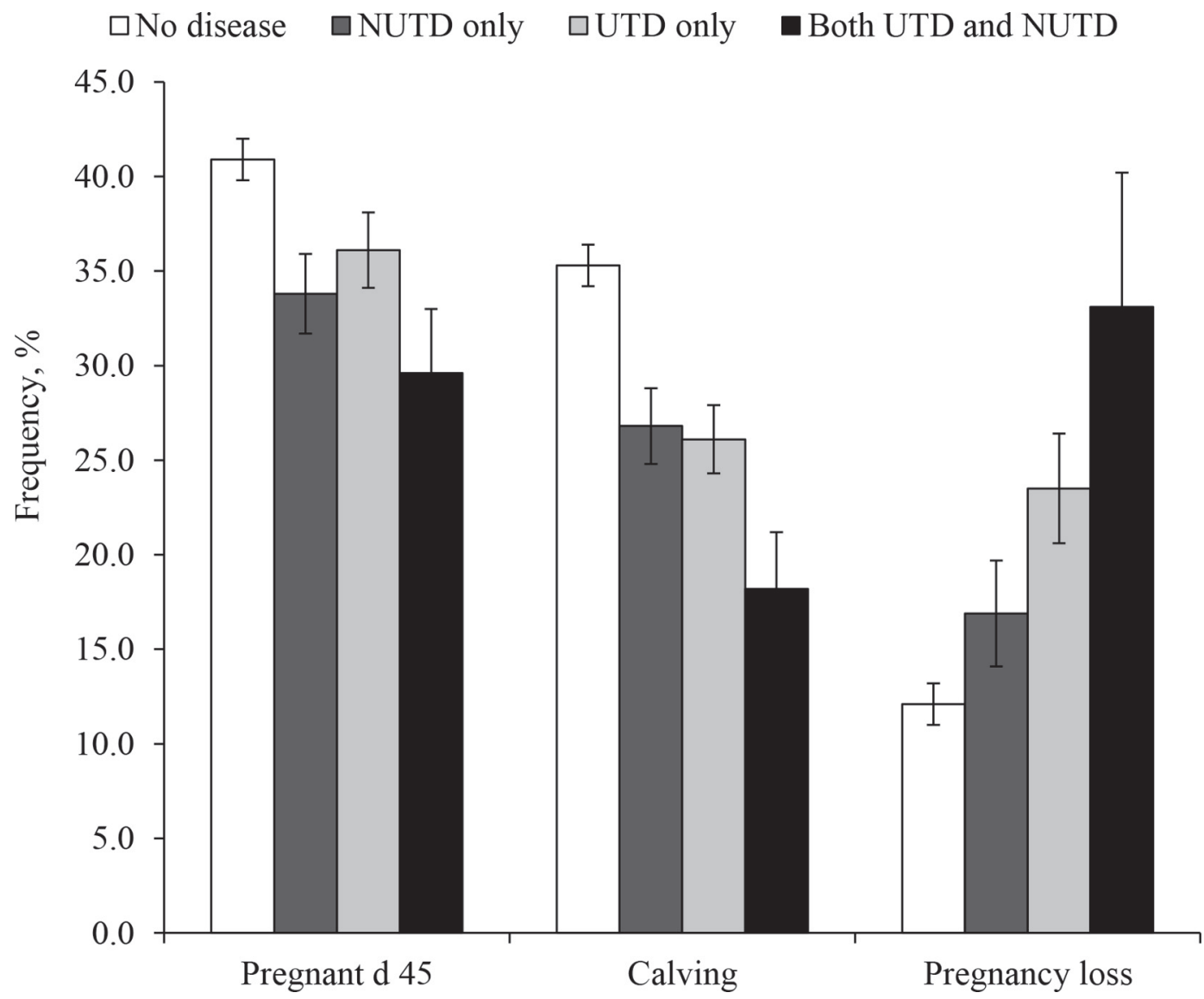

Figure 3. Pregnancy per breeding on d 45 after breeding, calving per breeding, and pregnancy loss from d 45 to term according to the incidence of uterine (UTD) and nonuterine disease (NUTD) in study 2. For pregnancy on d 45 , effect of UTD $(P=0.05)$, NUTD $(P<0.01)$, interaction between UTD and NUTD $(P=0.96)$, and additive effect of UTD and NUTD $(P=0.16)$ were noted. For calving, effect of UTD $(P$ $<0.05)$, NUTD $(P<0.01)$, interaction between UTD and NUTD $(P=0.79)$, and additive effect of UTD and NUTD $(P=0.02)$ were observed. For pregnancy loss, effect of UTD $(P<0.01)$, NUTD $(P=0.04)$, interaction between UTD and NUTD $(P=0.83)$, and additive effect of UTD and NUTD $(P=0.05)$ were seen. Error bars represent the SEM.

\section{Study 3: Effect of Disease on Development to the Morula Stage}

A total of 597 cows out of 635 (94\%) had synchronized ovulation following AI and had the uterus flushed on d 5 or 6 after AI for recovery of ova or embryos (Table 1). From those, 419 flushings $(70.2 \%)$ resulted in a recovered ovum-embryo of which $347(82.8 \%)$ were cleaved. A total of 280 embryos were considered to be live, whereas 67 were degenerated. Live embryos represented $66.8 \%$ of all ova-embryos recovered and $80.7 \%$ of all embryos recovered. A total of 233 ova-embryos were classified as high quality, which represented $55.6 \%$ of all ova-embryos and $67.1 \%$ of embryos recovered.

The incidence of disease before AI was $41.9 \%$. The incidences of UTD and NUTD were 22.0 and $28.8 \%$, respectively. Incidence of disease before AI reduced the proportion of cleaved, live, and high-quality embryos relative to ova-embryos recovered, as well as the proportion of live and high-quality embryos relative to em- bryos recovered (Figure 7A). The results were similar when data were modeled according to UTD (Figure 7B) and NUTD (Figure 7C) separately, except for the proportion of cleaved ova, which were affected by UTD but not by NUTD (Figure 7).

\section{Study 4: Effect of Disease on Conceptus Development and Transcriptome}

Interferon- $\tau$ was detected in the uterine fluid in 70 of 148 cows (47.3\%), and these cows were considered pregnant. From those, 52 conceptuses were recovered. The incidence of disease before AI was $45.3 \%$. The incidences of UTD and NUTD were 32.4 and $21.6 \%$, respectively. Disease did not affect $(P=0.93)$ pregnancy on d 15 to 16 (Figure 8A), but resulted in shorter conceptuses (Figure 8B) and reduced concentration of IFN- $\tau$ in the uterine flush (Figure $8 \mathrm{C}$ ). Similar results were observed when data were modeled according to UTD or NUTD. Cows diagnosed with UTD had shorter 
A $\quad$ aNo NUTD - preantral $\quad$ NUTD - preantral
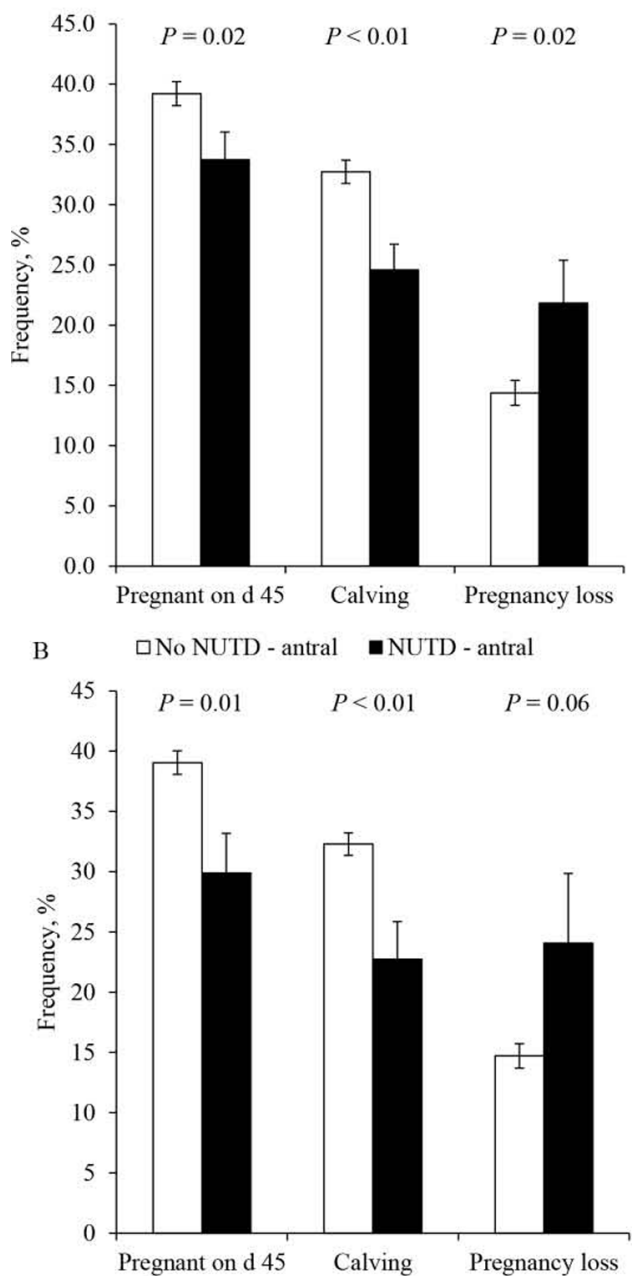

C

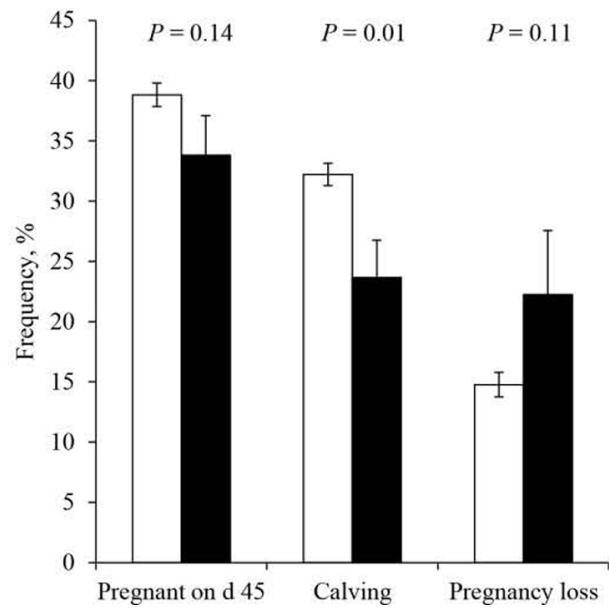

Figure 4. Pregnancy per breeding on d 45 after breeding, calving per breeding, and pregnancy loss from d 45 to term according to the incidence of nonuterine diseases (NUTD) during the preantral period of ovulatory follicle development ( $\mathrm{d}-43$ or less relative to breeding; A), antral period of ovulatory follicle development ( $\mathrm{d}-42$ to -1 relative to breeding; $\mathrm{B}$ ), and early postbreeding period ( $\mathrm{d} 0$ to 42 relative to breeding; C) in study 2. Error bars represent the SEM.
$(P<0.01)$ conceptus than those without uterine disease. Cows with NUTD also had shorter $(P=0.02)$ conceptus than those without NUTD. Because of the shorter conceptus, cows with UTD $(P=0.06)$ and those with NUTD $(P=0.07)$ tended to have reduced concentrations of IFN- $\tau$ in the uterine fluid. Disease reduced $(P<0.05)$ the concentration of progesterone in all cows (Figure 8D). Nonetheless, progesterone in the first $15 \mathrm{~d}$ of gestation in pregnant cows did not differ with disease (Figure 8E).

Transcriptome analyses revealed few genes differently expressed between conceptuses recovered from cows previously diagnosed and those not diagnosed by NUTD before AI (Table 2). Only 7 transcripts were differently expressed: 4 downregulated and 3 upregulated in d 15 conceptuses from NUTD cows. For d-16 conceptuses, 35 transcripts were differently expressed: 9 downregulated and 26 upregulated in NUTD cows. Functional analysis revealed that the main diseases and disorders associated with the differently expressed genes on d-16 conceptuses were inflammatory disease (11 molecules; $O P<0.04)$, immunological disease (11 molecules; $O P<0.05$ ), and connective tissue disorders (8 molecules; $O P<0.05)$. Figure 9 depicts a network generated by the Ingenuity Pathway Analysis focusing on 15 genes differently expressed and their associated diseases and functions. Network score was 40 and the associated top diseases and functions in the network were cancer, organismal injury and abnormality, and reproductive system disease.

Three potential upstream regulators of the changes in transcriptome were identified and they all had predicted increased activity (Figure 10). These were LPS $(O P=8.5 \mathrm{E}-04, Z S=2.4)$, IFN- $\gamma(O P=4.1 \mathrm{E}-03, Z S$ $=2.4)$, and tumor necrosis factor $(O P=5.7 \mathrm{E}-02, Z S$ $=2.2$ ). Two potential downstream effects of the differently expressed genes with very small $O P$ values were activation of cells $(O P=4.2 \mathrm{E}-05, Z S=1.7 ;$ Figure $11 \mathrm{~A})$ and systemic autoimmune syndrome $(O P=4.8 \mathrm{E}-$ 05, effect not predicted; Figure 11B). In addition, the most significant canonical pathways included OX40 signaling pathway $(O P=5.0 \mathrm{E}-05)$, type I diabetes mellitus signaling $(O P=6.5 \mathrm{E}-04)$, antigen presentation pathway $(O P=1.1 \mathrm{E}-03)$, graft-versus-host disease signaling $(O P=1.1 \mathrm{E}-03)$, and allograft rejection signaling $(O P=1.4 \mathrm{E}-03)$.

\section{Study 5: Effect of Disease on Blood Immune Cell Responses to IFN-T}

The incidence of disease in cows in this study was 29.6\%. The incidences of UTD and NUTD were 14.9 and $19.0 \%$, respectively. The pregnancies per AI were $41.0 \%$ on d 32 and $35.9 \%$ on d 64 after AI. Pregnant 


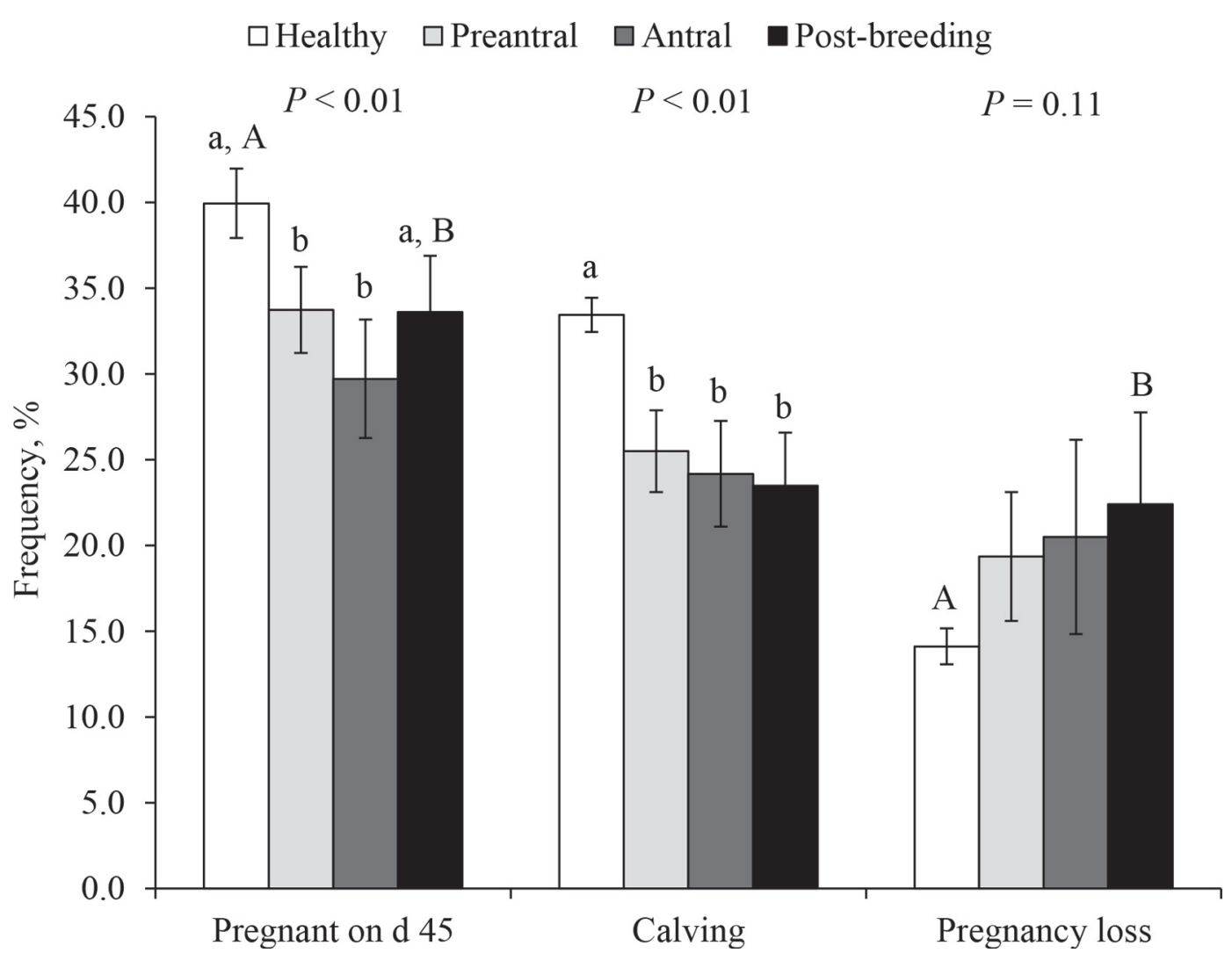

Figure 5. Pregnancy per breeding on d 45 after breeding, calving per breeding, and pregnancy loss from d 45 to term according to the period of occurrence of the last nonuterine disease (NUTD) diagnosis in study 2. Disease was diagnosed during the estimated period of preantral of ovulatory follicle development ( $\mathrm{d}-43$ or less relative to breeding), antral period of ovulatory follicle development ( $\mathrm{d}-42$ to -1 relative to breeding), and early postbreeding period (d 0 to 42 relative to breeding). Cows that did not suffer from NUTD were classified as healthy. Different lowercase letters $(\mathrm{a}, \mathrm{b})$ denote statistical difference $(P<0.05)$; different uppercase letters $(\mathrm{A}, \mathrm{B})$ denote tendency for statistical effect $(P<0.07)$. Error bars represent the SEM.

cows had increased $(P<0.01)$ expression of the 2 ISG investigated. Transcript expression of ISG15 and RTP4 in PBL were 2.4 and 1.4 fold increased, respectively, in cows diagnosed pregnant on d 64 after AI compared with those diagnosed nonpregnant. An interaction $(P$ $=0.04$ ) between disease category and pregnancy was detected for expression of ISG15 (Figure 12A) because pregnancy increased normalized expression of ISG15 in cows without disease, but not in cows previously diagnosed with disease. Similar to ISG15, normalized expression of RTP4 increased with pregnancy in cows without disease, but not in cows previously diagnosed with disease (Figure 12B).

\section{DISCUSSION}

The current study presents compelling evidence for the carryover negative effects of inflammatory diseases diagnosed before breeding on the developmental biology and reproductive performance in dairy cows. Collectively, they show that cows diagnosed with disease from parturition to the day before breeding have reduced cleavage of potential zygotes, reduced survival of zygotes to the morula stage, impaired development to early stages of conceptus elongation, reduced secretion of IFN- $\tau$ during the period of pregnancy recognition, distinct responses of ISG in PBL at onset of implantation, increased pregnancy loss, and, consequently, reduced pregnancy and calving per breeding. The altered developmental biology in cows diagnosed with disease before breeding could be the result of compromised oocyte developmental competence, impaired uterine ability to support a healthy pregnancy, or a combination of both. The present results provide new insights on possible mechanism on how disease affects developmental biology, the biological processes implicated with the carryover effects, and the importance of the site and time of the inflammation event.

The clinical diseases commonly occurring in dairy herds and investigated in our study usually result from microbial infections or tissue injury, which in turn lead to a series of physiological adaptations not only locally 
A

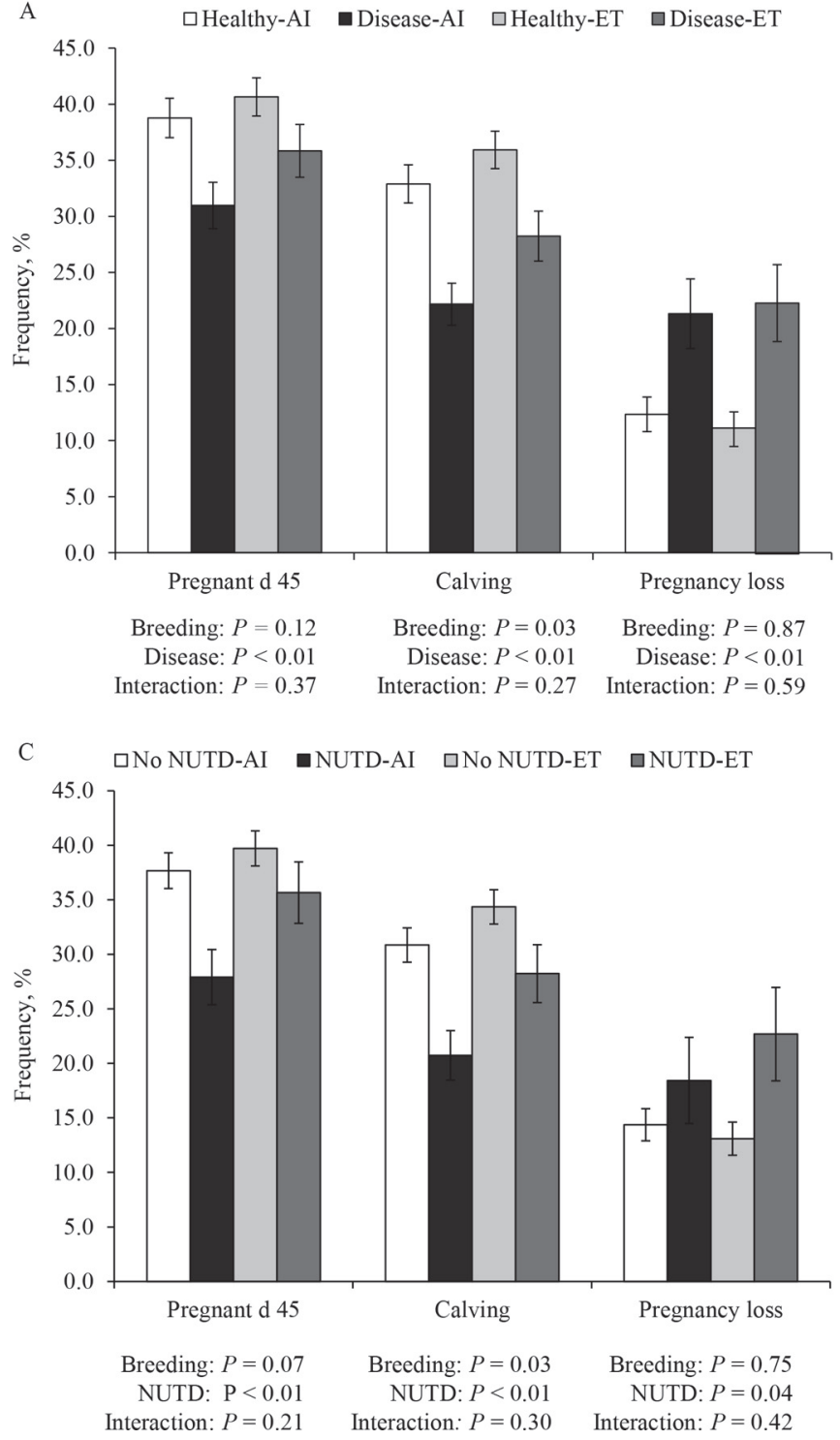

B $\square$ No UTD-AI $\square$ UTD-AI $\square$ No UTD-ET $\square$ UTD-ET

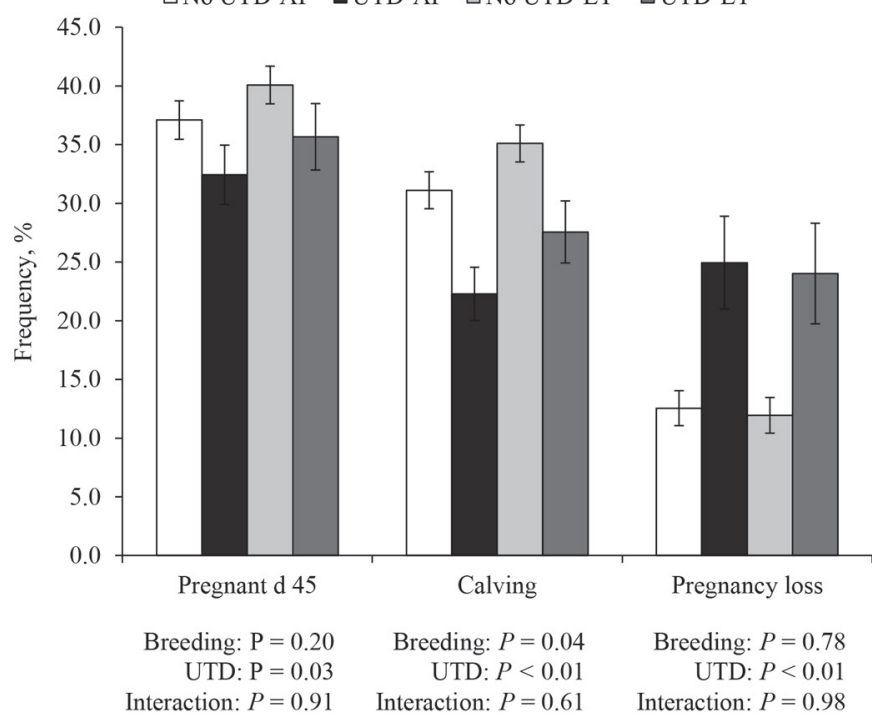

Figure 6. Pregnancy per breeding on d 45 after breeding, calving per breeding, and pregnancy loss from d 45 to term according to type of breeding, AI, or embryo transfer (ET) and the incidence of disease (A), uterine disease (UTD; B), and nonuterine disease (NUTD; C) in study 2. Statistical values indicate the effect of breeding type (AI vs. ET), disease (yes vs. no; A), uterine disease (yes vs. no; B), and nonuterine disease (yes vs. no; C), and interaction between breeding type and disease. Error bars represent the SEM.

in the tissue affected but also systemically in the organism (Colditz, 2002). One of the first responses of the affected tissue to an insult is inflammation, which is mediated by the secretion of inflammatory molecules such as cytokines, chemokines, eicosanoids, and vasoactive amines. These inflammatory mediators recruit immune cells to the site of injury and induce production of hepatic plasma proteins with the purpose of contain-

Table 1. Outcomes from uterine flushing on d 5 or 6 after first AI postpartum in lactating dairy cows

\begin{tabular}{lccc}
\hline Item & Number & Ova-embryos recovered (\%) & Embryos recovered (\%) \\
\hline Flushing & 597 & - & - \\
Recovered ova-embryos & 419 & 100 & - \\
Cleaved embryos & 347 & 82.8 & 800 \\
Live embryos & 280 & 66.8 & 67.1 \\
High-quality embryos & 233 & 55.6 & \\
\hline
\end{tabular}


A

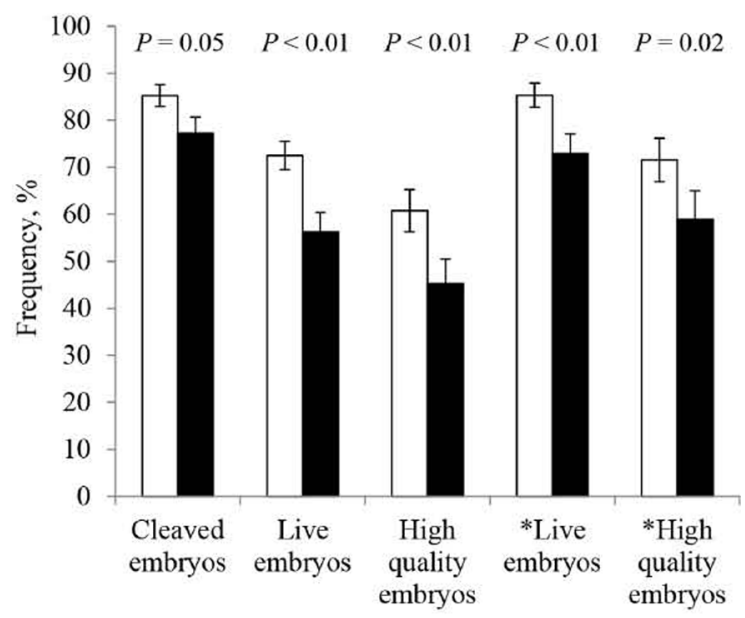

B

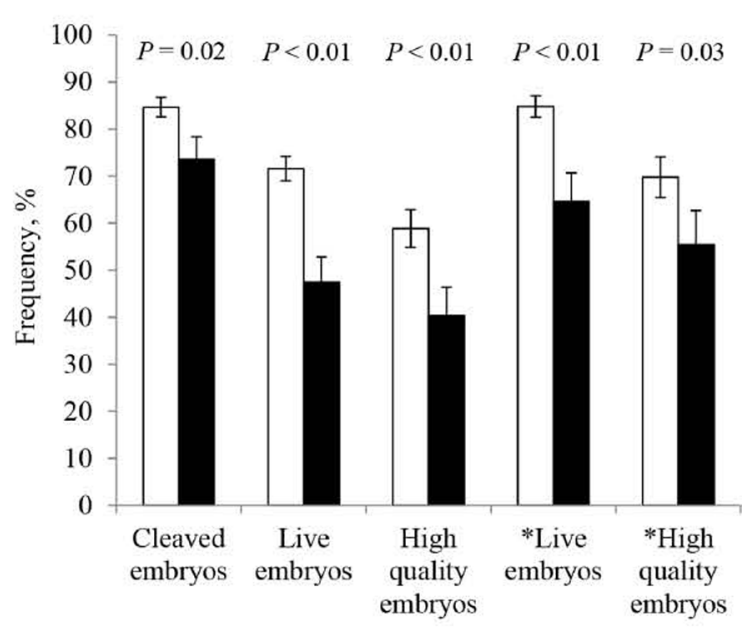

C

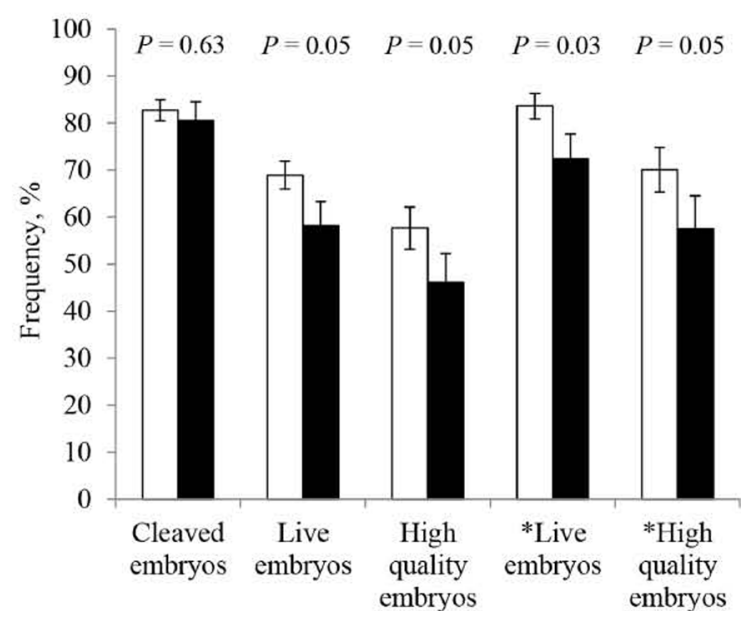

Figure 7. Cleaved embryos, live embryos (grades 1 to 3), and highquality embryos (grades 1 and 2) as percentage of ova-embryos recovered (without an asterisk) or as percentage of embryos recovered (with an asterisk), according to the incidence of disease (A), uterine diseases (UTD; B), and nonuterine diseases (NUTD; C). Error bars represent the SEM. ing the infection or tissue injury (Medzhitov, 2008). Nonetheless, inflammation has consequences for energy metabolism of cattle (Gifford et al., 2012) and, when exacerbated, may generate excessive oxidative stress and further tissue damage and dysfunction (Medzhitov, 2008; Gifford et al., 2012).

In general, cattle affected by diseases have reduced appetite, increased BW loss, and altered partition of nutrients (Gifford et al., 2012). The reduced appetite after establishment of disease seems to be a conserved behavior in mammals and birds that is explained by the communication between the immune and the central nervous systems (Dantzer and Kelley, 2007; McCusker and Kelley, 2013). Proinflammatory cytokines produced in the infected tissue act in the brain to induce common symptoms of sickness, commonly described as cytokine-induced sickness behavior (Dantzer and Kelley, 2007). Inflammation not only reduces nutrient intake but also increases energy expenditure to mount a response against infection (Colditz, 2002; Demas et al., 2003; Romanyukha et al., 2006). This energy cost partitions resources away from other physiological processes, including production, reproduction, and perhaps even the immune system itself (Gifford et al., 2012). Therefore, reduced nutrient intake, increased energy and AA expenditure, and altered nutrient partition likely worsens the nutrient balance of postpartum cows, which in turn has known consequences for reproduction (Butler, 2003; Walsh et al., 2007; Santos et al., 2009). Many inflammatory diseases induce fever, and hyperthermia is a well-characterized phenomenon that compromises reproduction in cattle by disrupting oocyte and embryonic development and altering uterine function (Hansen, 2009), which typically lasts months after the injury has ceased.

Incidence of clinical diseases increases the proportion of anovular cows at the end of voluntary waiting period and the proportion of cows with low BCS at first AI postpartum, which are 2 factors known to reduce $\mathrm{P} / \mathrm{AI}$ in cows subjected to estrous synchronization programs (Santos et al., 2009). Nevertheless, the negative effect of disease on reproduction does not seem to be dependent on the resulting increase in anovular cows or cows with low BCS. In fact, results presented herein showed that disease and anovulation or low BCS have additive effects. We showed that disease before breeding reduced the risk of pregnancy in cows that were estrous cyclic at the end of voluntary period and in those with adequate BCS at the time of breeding; however, when cows had combined disease and anovulation or disease and low BCS, then the depression in fertility was exacerbated. Collectively, these results suggest that the carryover effects of disease on reproduction of dairy cows cannot be explained simply by the nutritional status and its 
consequences to BCS and estrous cyclicity at the onset of breeding postpartum.

The inflammatory mediators produced by the injured tissues and liver can also reach the reproductive tract, including ovaries and uterus, but also the brain, which influences the physiological processes that control normal reproductive cycles. Studies in which LPS was infused into the uterus, mammary gland, or intravenously resulted in reduced secretion of $\mathrm{LH}$ (Peter et al., 1989; Lavon et al., 2008). Cows that suffered from uterine disease postpartum had delayed growth of the first dominant follicle postpartum and reduced concentrations of estradiol (Sheldon et al., 2002). Presence of LPS in the follicular fluid of cows with uterine diseases has been postulated as a potential reason for compromised steroidogenesis, follicle growth, and impaired oocyte developmental competence (Bromfield et al., 2015). Granulosa cells possess pattern recognition re-
A

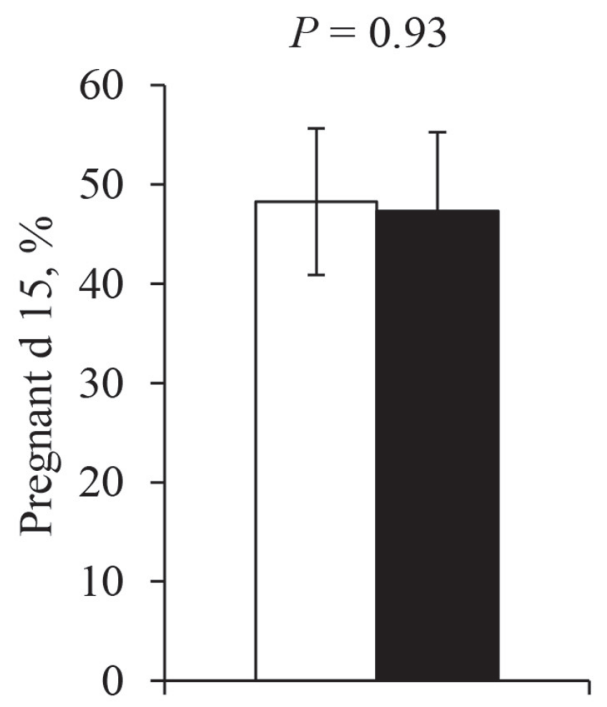

B $\square$ No disease $\square$ Disease

$P<0.01$

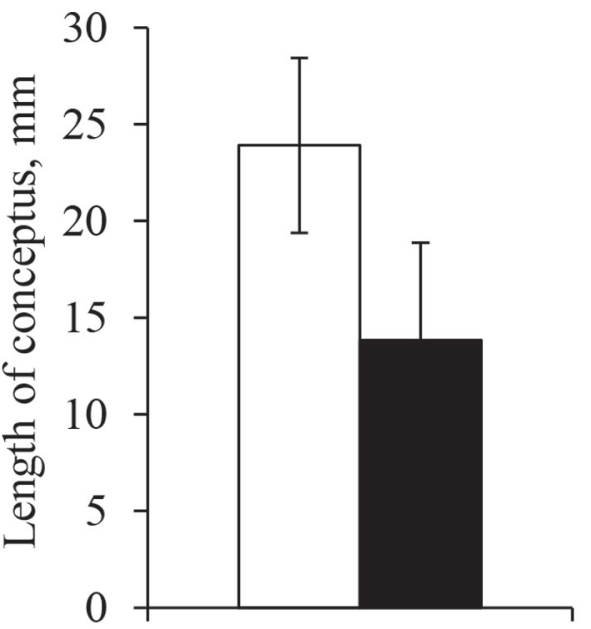

C $\square$ No disease $\square$ Disease

$P=0.02$

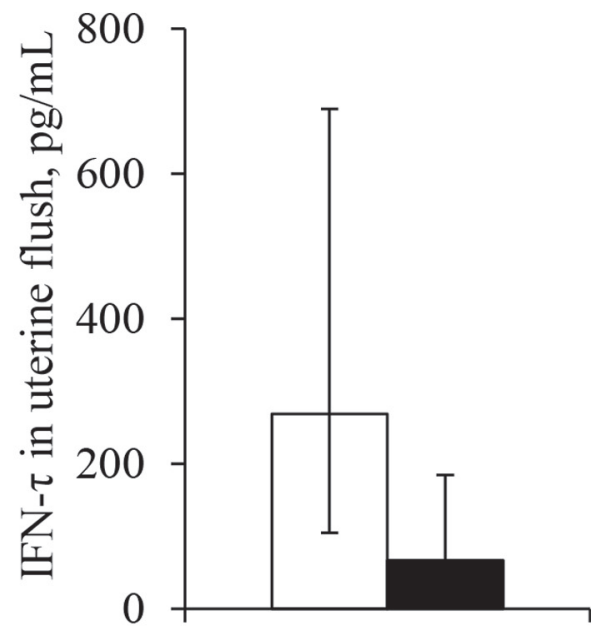

D

$\square$ No disease $\square$ Disease

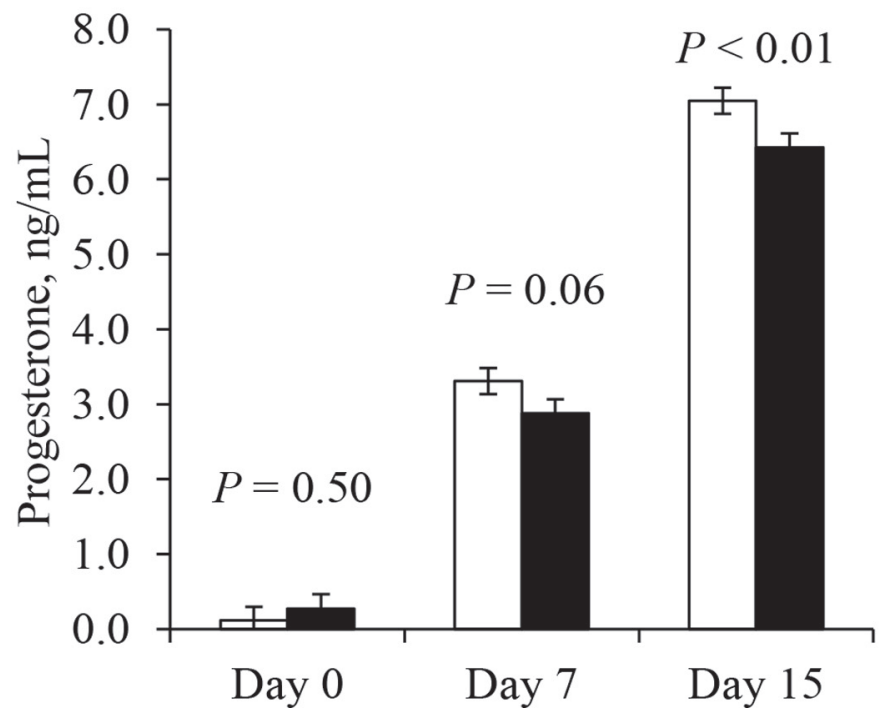

$\mathrm{E}$
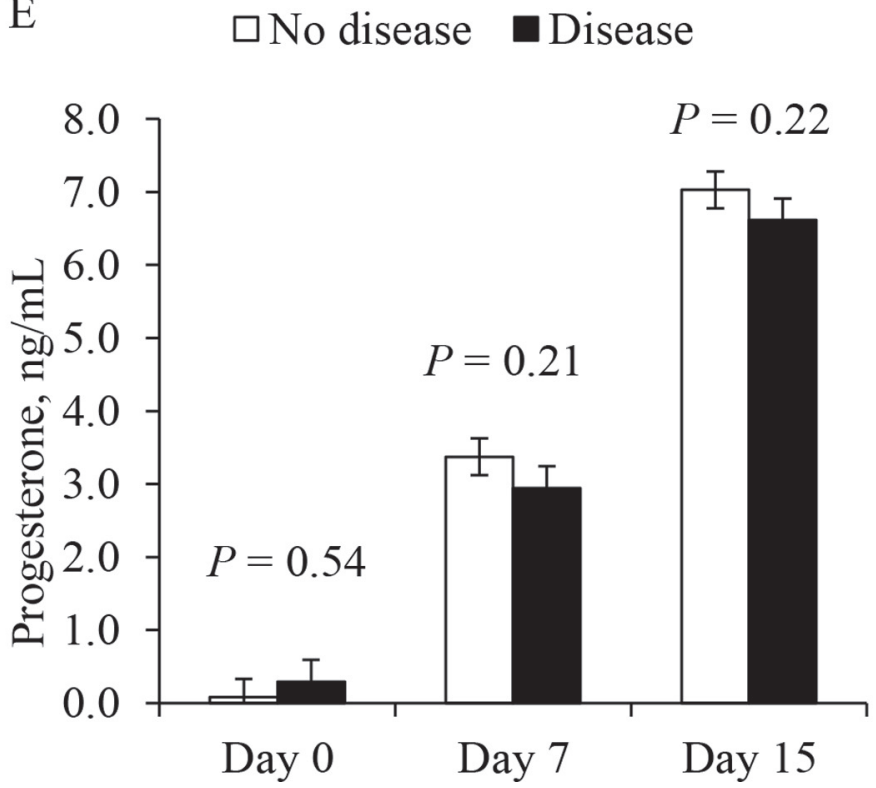

Figure 8. Pregnancy per AI on d 15 based on detection of IFN- $\tau$ in the uterine flush (A); length of the recovered intact conceptuses (B); concentration of IFN- $\tau$ in the uterine flush of pregnant cows (C); and progesterone concentration on d 0, 7, and 15 relative to AI in all cows (D) or in pregnant cows (E) according to the incidence of disease before AI. Error bars represent the SEM for all panels except for panel C, which represent the $95 \%$ CI of the back-transformed adjusted means. 
ceptors, such as toll-like receptor 4 , and are capable of initiating an inflammatory response against pathogenassociated molecular patterns by secreting cytokines, which potentially impair follicle steroidogenesis and oocyte meiotic competence (Bromfield and Sheldon, 2011). In fact, incubation of granulosa cells with LPS or tumor necrosis factor- $\alpha$ resulted in smaller production of estradiol (Williams et al., 2008). In addition, reduced nutrient balance would likely decrease the concentrations of glucose, insulin, and IGF-1, which in turn can further compromise follicle growth and steroidogenesis (Butler, 2003).

It is important, however, to put in perspective the time of disease occurrence relative to breeding and embryo development. Seventy to eighty percent of the cases of clinical inflammatory diseases occurred in the first $3 \mathrm{wk}$ postpartum. Because the typical voluntary waiting period in most farms is 50 to $60 \mathrm{~d}$ (NAHMS,
2009), the first breeding postpartum in most cows diagnosed with disease typically occur 6 to 8 wk after clinical recovery from the illness. In the current study, the DIM at first breeding averaged 81 , and $50 \%$ of the cows were bred after 77 DIM, many weeks after the diagnosis of disease. Unless chronic inflammation is established, inflammatory mediators are unlikely to be present by the time of breeding or when early embryo development occurs in cows previously affected by postpartum diseases. A potential effect of the disease on preantral follicles is one of the plausible mechanisms mediating the carryover effects of disease on reproduction. Disease could potentially disturb follicle environment and oocyte developmental competence without affecting its ability to fully grow and ovulate (Bromfield et al., 2015). In fact, data presented in the current study show that NUTD occurring in the preantral stages of ovulatory follicle development had similar negative effects

Table 2. Probe set identification, annotated gene symbol, and log fold ratio for transcripts differently expressed in conceptuses recovered from cows diagnosed with nonuterine diseases before AI compared with conceptuses recovered from cows that were not diagnosed with nonuterine disease before AI

Conceptuses recovered on d 15

Probe identification

Bt.19823.1.A1_at

Bt.140.1.S1_at

Bt.20381.2.S1_at

$\begin{array}{ll} & \text { Gene symb } \\ \text { CD36 } \\ \text { TRAM2 } \\ \text { OXTR } \\ \text { F2R }\end{array}$

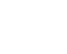

$\begin{array}{lll}\text { Bt.26998.1.A1_s_at } & T N N C 1 & 0.69 \\ \text { Bt.13324.1.S1_a_at } & I D H 1 & 0.74 \\ \text { Bt.29237.1.A1_at } & - & 0.87\end{array}$

\section{Conceptuses recovered on d 16}

\begin{tabular}{|c|c|c|}
\hline Probe identification & Gene symbol & Log fold ratio ${ }^{1}$ \\
\hline Bt.2129.1.S1_at & $V C A N$ & -1.84 \\
\hline Bt.2129.2.S1_at & $V C A N$ & -1.75 \\
\hline Bt.14240.1.S1_at & $F L N C$ & -1.32 \\
\hline Bt.22644.2.A1_at & - & -1.19 \\
\hline Bt.12685.1.S1_at & $M Y H 11$ & -0.81 \\
\hline Bt.9158.1.A1_at & $F A M 65 B$ & -0.76 \\
\hline Bt.9901.1.S1_at & - & -0.74 \\
\hline Bt.8674.1.A1_at & - & -0.70 \\
\hline Bt.28621.1.S1_at & - & -0.69 \\
\hline Bt.7872.1.S1_at & LOC100335345 & 0.59 \\
\hline Bt.13278.1.S1_at & STEAP3 & 0.60 \\
\hline Bt.440.1.S1_at & $N T S$ & 0.61 \\
\hline Bt.24228.1.S1_at & LOC504309 & 0.63 \\
\hline Bt.9027.1.S1_at & NFKBIA & 0.64 \\
\hline Bt.8552.1.S1_at & $B O L A-D R A$ & 0.76 \\
\hline Bt.2346.1.S1_at & $L Y 6 E$ & 0.77 \\
\hline Bt.1132.2.S1_at & FZD3 & 0.78 \\
\hline Bt.9632.2.S1_at & $D M B T 1$ & 0.78 \\
\hline Bt.5356.1.S1_s_at & $B o L A-D R B 3$ & 0.80 \\
\hline Bt.22978.1.S1_a_at & IFITM1 & 0.80 \\
\hline Bt.15713.1.A1_at & PLEK & 0.81 \\
\hline Bt.5878.1.A1_at & $S D S$ & 0.86 \\
\hline Bt.9596.1.S1_at & TFF3 & 1.06 \\
\hline Bt.8967.1.S1_at & $M S T N$ & 1.15 \\
\hline Bt.15957.1.S1_at & - & 1.16 \\
\hline Bt.9683.1.A1_at & $L Y 6 G 6 E$ & 1.18 \\
\hline Bt.357.1.S1_at & S100A12 & 1.60 \\
\hline Bt.7033.2.S1_a_at & FOLR1 & 1.69 \\
\hline Bt.22797.1.A1_at & ENPP5 & 1.72 \\
\hline Bt.7912.1.A1_at & SORL1 & 2.03 \\
\hline Bt.16048.1.S1_at & $S R G N$ & 2.46 \\
\hline Bt.27283.1.S1_x_at & $B O L A$ & 2.53 \\
\hline Bt.29129.1.S1_at & AGR2 & 2.63 \\
\hline Bt.278.1.S1_at & $S A A 3$ & 3.03 \\
\hline Bt.4802.1.S1_at & $L T F$ & 4.57 \\
\hline
\end{tabular}

$\overline{{ }^{1} \text { Conceptuses recovered from cows that were not diagnosed with nonuterine disease were used as reference for comparison. Bolded cells have }}$ positive log fold ratio values.

Journal of Dairy Science Vol. 99 No. 3, 2016 


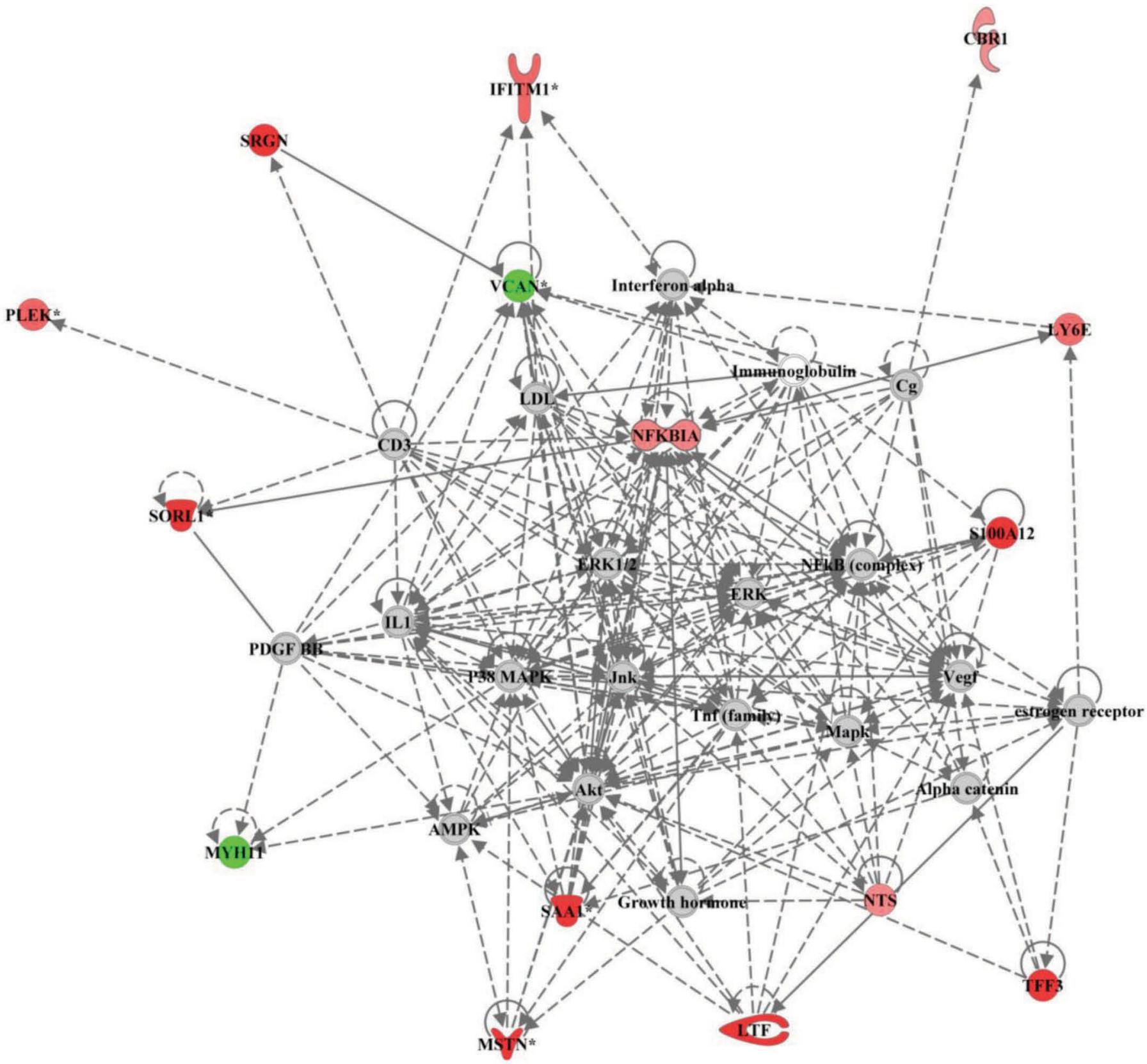

Figure 9. Networks generated by Ingenuity Pathway Analysis software (Qiagen, Redwood City, CA) focusing on 15 genes differently expressed between conceptus recovered from cows diagnosed with nonuterine diseases before AI and those recovered from cows not diagnosed with nonuterine diseases before AI. Network score was 40 and the associated top diseases and functions in the network were cancer, organismal injury and abnormality, and reproductive system disease. Red represents genes upregulated and green represents genes downregulated in conceptuses recovered from cows diagnosed with nonuterine diseases before AI. Solid and dashed lines imply direct and indirect relationships, respectively. The pointed and blunted arrowheads represent activating and inhibitory relationships, respectively. Color version available online.

on pregnancy to that of NUTD occurring during the antral stages of ovulatory follicle development or the early stages of embryonic development. The potential effect of inflammatory diseases on oocyte competence and early embryo development, however, does not completely explain the reduced fertility in dairy cows. Cows diagnosed with disease before breeding and receiving a healthy embryo on d 7 of the estrous cycle had reduced pregnancy per ET compared with those that received a similar embryo, but were not diagnosed with disease before transfer. These results suggest that the endometrium or the uterine environment in general is also affected by disease, which impairs the ability to support the pregnancy to term. This was observed in cows 


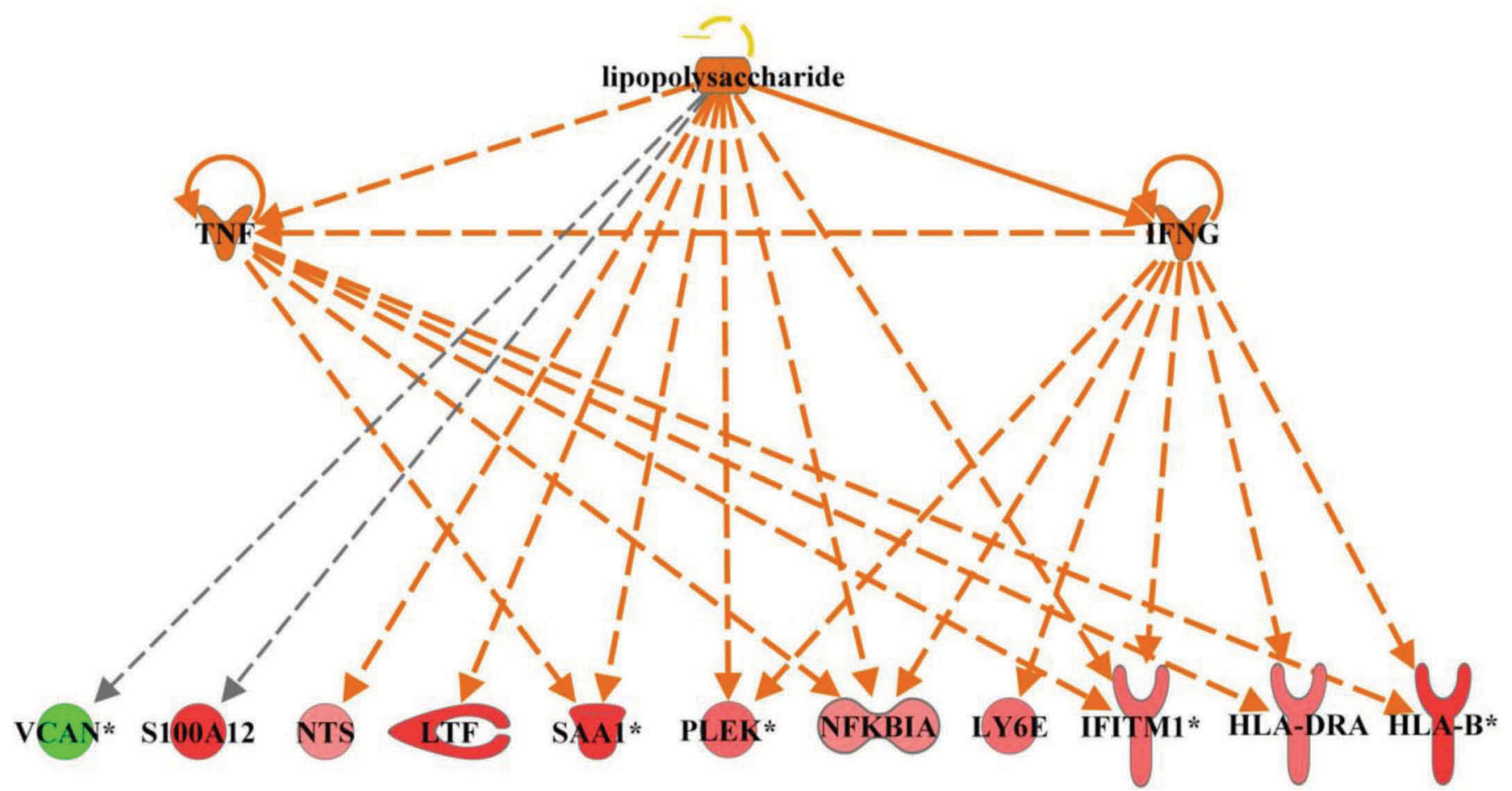

Figure 10. Network generated from causal analysis in the Ingenuity Pathway Analysis software (Qiagen, Redwood City, CA) of 11 genes differently expressed between conceptus recovered from cows diagnosed with nonuterine diseases before AI and those recovered from cows that were not diagnosed with nonuterine diseases before AI and 3 potential upstream regulators with predicted increased activity. Red denotes genes upregulated and green denotes genes downregulated in conceptus recovered from cows diagnosed with nonuterine diseases before AI. The pointed and blunted arrowheads represent activating and inhibitory relationships, respectively. Solid and dashed lines imply on direct and indirect relationships, respectively. Orange represents predicted activation and relationships that lead to activation and gray represents an effect not predicted. Color version available online.

affected by UTD or by NUTD, thereby suggesting that both have carryover effects on the uterine environment.

The effect of UTD on uterine biology during early development may be a result of local lesions caused by bacterial infection and resulting inflammation that might persist. Infection of the endometrium, especially caused by Trueperella pyogenes, damages the superficial and glandular epithelium and causes severe diffuse inflammation (Miller et al., 2007; Lima et al., 2015). In 20 to $30 \%$ of the cases, treatment with antimicrobials does not necessarily result in clinical cure (Lima et al., 2014), suggesting persistence of the bacterial agent and the concurrent inflammatory process. Persistent infection can induce chronic inflammation with abnormal uterine glands that present extensive lymphocytic and eosinophilic infiltration and necrosis (Cupps, 1973). Consecutive cytological examinations of the endometrium showed that approximately $40 \%$ of the cows did not resolve inflammation by 46 DIM, and these cows have reduced $\mathrm{P} / \mathrm{AI}$ and increased pregnancy loss compared with those that resolved the uterine inflammation postpartum (Lima et al., 2013). Disrupted endometrial physiology by the time of breeding may not support the developing embryo or conceptus, and the presence of inflammation might also disrupt embryonic cell biology and conceptus development. Moreover, nutrient partition in cows suffering from clinical UTD may further impair uterine involution and recovery from infection. Wathes et al. (2009) evaluated the transcriptome of the endometrium of cows at 2 wk postpartum and reported that several transcripts linked with inflammation and active immune response were upregulated in cows undergoing severe negative energy balance compared with those exhibiting a more modest caloric deficit.

The mechanism on how NUTD reduce pregnancy in dairy cows, particularly those receiving an embryo is likely to be complex. Evidence exists for the participation of immune cells in the uterine biology during pregnancy in cattle (Oliveira et al., 2010; Ott and Gifford, 2010; Fair, 2015). Nonuterine diseases occurring before breeding could prime the immune system for a long-term unbalance of immune cell population or activity that compromises the uterine support for development and survival of the conceptus. Evaluation of preimplantation conceptuses at early stages of elongation showed that NUTD cows had smaller conceptus 
A

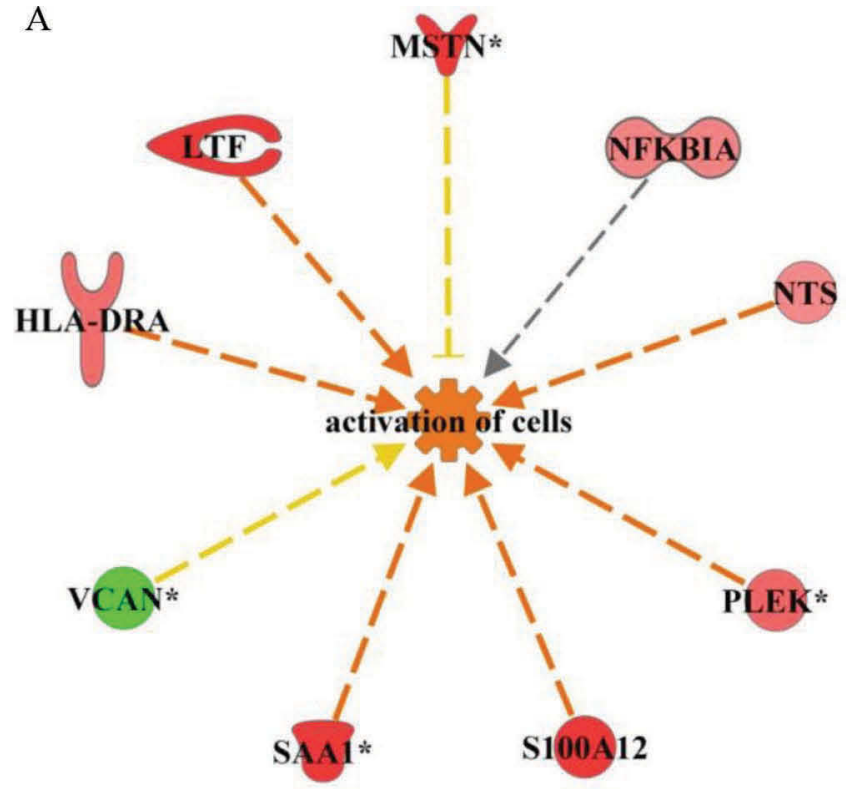

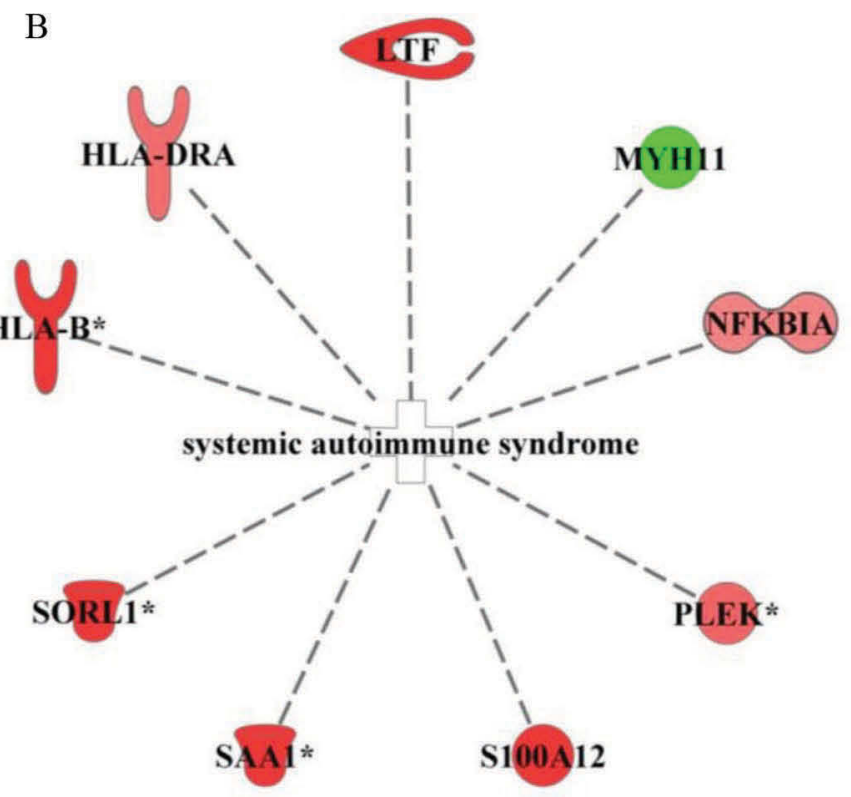

Figure 11. Potential downstream effects of genes differently expressed between conceptus recovered from cows diagnosed or not with nonuterine diseases before AI pointed by causal analysis in the Ingenuity Pathway Analysis software (Qiagen, Redwood City, CA). (A) Activation of cells (overlap $P$-value $=4.2 \mathrm{E}-05, \mathrm{Z}$-score $=1.7) ;(B)$ systemic autoimmune syndrome (overlap $P$-value $=4.8 \mathrm{E}-05$, effect not predicted). Red denotes genes upregulated and green denotes genes downregulated in conceptus recovered from cows diagnosed with nonuterine diseases before AI. The pointed and blunted arrowheads represent activating and inhibitory relationships, respectively. Solid and dashed lines imply on direct and indirect relationships, respectively. Orange represents predicted activation and relationships that lead to activation; gray represents effects not predicted; and yellow represents finding inconsistent with the predicted state of downstream function. Color version available online.

and consequently less secretion of IFN- $\tau$ in the uterine lumen. Impaired conceptus elongation and cross-talk with the endometrium through IFN- $\tau$ could be critical for the synchrony of pregnancy recognition and early placentation events (Thatcher et al., 1989). In support of the disruption of conceptus development with disease, functional analysis of the genes differentially expressed between diseased and nondiseased cows demonstrated changes that are potentially important for conceptus survival. Three proinflammatory molecules, LPS, IFN- $\gamma$, and tumor necrosis factor, were predicted as potential upstream regulators of the changes in transcriptome observed in conceptuses recovered from diseased cows. Moreover, the potential downstream consequences of these changes would include cell activation, particularly immune cells, and potential problems with tissue rejection by immune system, which could explain a potential rejection of the conceptus and pregnancy loss.

The developing conceptus is made up of maternal and paternal genes. Highly polymorphic proteins expressed from paternally inherited genes are potential sources of alloantigens that can be recognized as an allograft and potentially be rejected by the maternal immune system. Interestingly, expression of the major histocompatibility complex (MHC)-I heavy chain BOLA gene is downregulated during onset of elonga- tion (Ribeiro, 2015). Such change in gene expression suggests that the bovine conceptus cells reduce their ability to present antigens before the onset implantation, a strategy used by other species with more invasive placentation to escape the surveillance of immune cells (Bainbridge, 2000). Conceptuses from cows diagnosed with NUTD had upregulation of transcripts of MHC-I. Greater expression of MHC could represent a threat for conceptuses to escape the surveillance of the maternal immune system and not be rejected by it. In fact, bovine cloned conceptuses have greater expression of MHC-I, which is believed to be one of the reasons for the high incidence of pregnancy loss in cows carrying cloned embryos (Davies et al., 2004). Also, the increased expression of genes associated with inflammatory process, such as lactotransferrin, serum amyloid A3, and S100 Ca-binding protein A12, in conceptuses recovered from NUTD cows could also increase the recruitment or activation of immune cells to the conceptus-maternal interface and further increase the risk of tissue rejection and pregnancy loss.

The expression of ISG in PBL suggests that cows diagnosed with a disease before breeding have increased pregnancy loss at the onset of implantation. The increase in expression of ISG in diseased cows later diagnosed nonpregnant suggests that some of those were in fact pregnant on d 19 and secreting IFN- $\tau$, but lost 
A Nonpregnant on d $64 \quad \square$ Pregnant on d 64

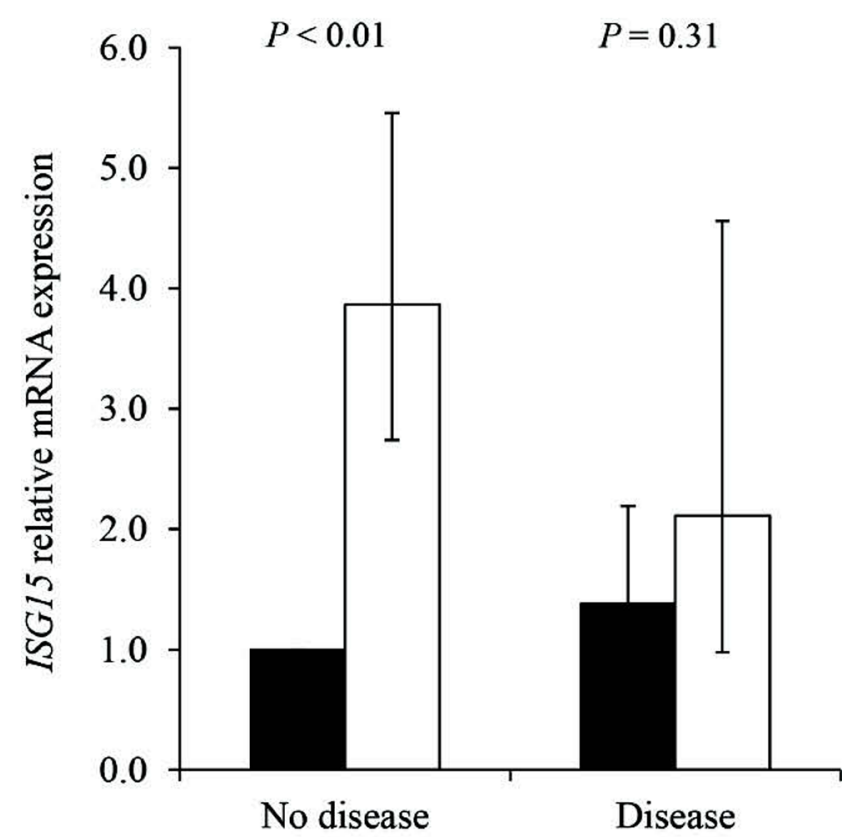

$P R E G<0.01 D I S=0.55 I N T=0.04$

B

- Nonpregnant on d $64 \quad \square$ Pregnant on d 64

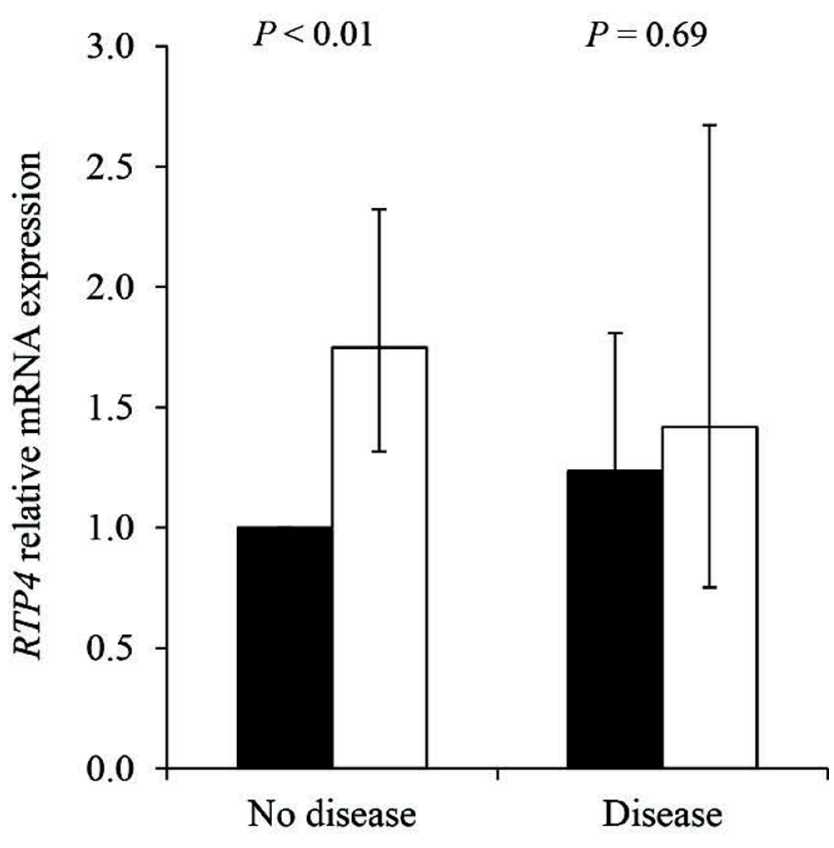

$P R E G=0.07 D I S=0.99 I N T=0.26$

Figure 12. Relative mRNA expression of interferon stimulated genes ISG15 (A) and RTP4 (B) in peripheral blood leukocytes samples on d 19 after AI according to pregnancy status on d 64 after AI and incidence of disease before AI. Error bars represent the $95 \%$ CI of the adjusted fold change. the pregnancy by d 62 after AI. On the other hand, the reduced expression of ISG in pregnant cows diagnosed with disease suggests that the conceptuses of those cows have reduced capacity to secrete IFN- $\tau$. As consequence, a distinct pattern was noted in ISG expression in PBL of pregnant between cows without disease and those diagnosed with disease. This change in conceptus development and IFN- $\tau$ secretion might have consequences for the uterine biology to support the gestation further (Ott and Gifford, 2010). In corroboration with this concept, it has been shown that the ISG response in PBL to pregnancy-produced molecules has been associated with fertility in lactating dairy cows (Ribeiro et al., 2014).

Among the transcripts differentially expressed by disease in d-15 conceptuses, the fatty acid translocase CD36 had the greatest difference in mRNA abundance. Conceptus cells recovered from disease cows did not express CD36, but the same gene was highly expressed in conceptus from healthy cows. The CD36 is a scavenger receptor related to cell adhesion and fatty acids uptake (Silverstein and Febbraio, 2009), 2 important cellular events during elongation (Ribeiro, 2015). Thus, the lack of expression of CD36 in conceptuses recovered from cows that suffered diseases might be related to their impaired elongation.

Fertilization based on cleavage was reduced in cows diagnosed with diseases. Interestingly, cleavage was affected only by UTD and not by NUTD. Thus, reduced fertilization in cows by UTD before breeding might suggest inadequate oviductal competence, which could impair transport or survival of oocytes or spermatozoa. The reduced survival to the morula stage and the quality of morulae recovered from cows diagnosed with both UTD and NUTD further suggest that oocyte quality or the oviduct are also contributors to the impaired developmental biology in dairy cattle. It is noteworthy that the carryover effects of inflammatory diseases extended from fertilization until late stages of gestation. Late pregnancy losses, those occurring after d 45 of gestation, increased in cows diagnosed with disease, thereby suggesting that the negative carryover consequence of disease persist longer than 4 mo. A better understanding of the cellular and molecular mechanisms leading to the long-term effects of diseases on developmental biology might help in the development of strategies to reduce pregnancy losses in cattle.

\section{CONCLUSIONS}

Diseases postpartum are prevalent in dairy herds and impair developmental biology and reproductive performance in dairy cows. Inflammatory disease before breeding reduced fertilization of oocytes and develop- 
ment to morula as well as impaired early conceptus elongation and secretion of IFN- $\tau$ in the uterine lumen. These changes in conceptus development were concurrent with inflammation-like changes in the transcriptome of conceptus cells, increased pregnancy loss, and reduced pregnancy and calving per breeding. The negative effects of disease on reproduction were observed independently of estrous cyclicity status and the BCS of cows, both of which are known to influence fertility of dairy cows. Disease at the preantral or antral stages of ovulatory follicle development had similar negative effect on pregnancy per AI and pregnancy losses. The carryover consequences of diseases on developmental biology seemed to be longer than 4 mo. The compromised maintenance of pregnancy in cows with disease when receiving an embryo suggests that reduced oocyte competence is not only a likely reason for the low fertility of this cohort of cows, but impaired uterine environment is also involved.

\section{REFERENCES}

Bainbridge, D. R. J. 2000. Evolution of mammalian pregnancy in the presence of the maternal immune system. Rev. Reprod. 5:67-74.

Bauman, D. E., and W. B. Currie. 1980. Partitioning of nutrients during pregnancy and lactation: A review of mechanisms involving homeostasis and homeorhesis. J. Dairy Sci. 63:1514-1529.

Benjamini, Y., and Y. Hochberg. 1995. Controlling the false discovery rate - A practical and powerful approach to multiple testing. J. R. Stat. Soc. Series B Stat. Methodol. 57:289-300.

Bisinotto, R. S., E. S. Ribeiro, and J. E. P. Santos. 2014. Synchronisation of ovulation for management of reproduction in dairy cows. Animal 8(Suppl. 1):151-159.

Bromfield, J. J., J. E. P. Santos, J. Block, R. S. Williams, and I. M. Sheldon. 2015. Physiology and endocrinology symposium: Uterine infection: Linking infection and innate immunity with infertility in the high-producing dairy cow. J. Anim. Sci. 93:2021-2033.

Bromfield, J. J., and I. M. Sheldon. 2011. Lipopolysaccharide initiates inflammation in bovine granulosa cells via the TLR4 pathway and perturbs oocyte meiotic progression in vitro. Endocrinology 152:5029-5040.

Butler, W. R. 2003. Energy balance relationships with follicular development, ovulation and fertility in postpartum dairy cows. Livest. Prod. Sci. 83:211-218.

Cerri, R. L. A., R. C. Chebel, F. Rivera, C. D. Narciso, R. A. Oliveira, W. W. Thatcher, and J. E. P. Santos. 2011. Concentration of progesterone during the development of the ovulatory follicle: I. Ovarian and embryonic responses. J. Dairy Sci. 94:3342-3351.

Cerri, R. L. A., S. O. Juchem, R. C. Chebel, H. M. Rutigliano, R. G. S. Bruno, K. N. Galvão, W. W. Thatcher, and J. E. P. Santos. 2009a. Effect of fat source differing in fatty acid profile on metabolic parameters, fertilization, and embryo quality in high-producing dairy cows. J. Dairy Sci. 92:1520-1531.

Cerri, R. L. A., H. M. Rutigliano, R. G. S. Bruno, R. C. Chebel, and J. E. P. Santos. 2009b. Period of dominance of the ovulatory follicle influences embryo quality in lactating dairy cows. Reproduction 137:813-823.

Cerri, R. L. A., H. M. Rutigliano, F. S. Lima, D. B. Araújo, and J. E. P. Santos. 2009c. Effect of source of supplemental selenium on uterine health and embryo quality in high-producing dairy cows. Theriogenology 71:1127-1137.

Colditz, I. G. 2002. Effects of the immune system on metabolism: Implication for production and disease resistance in livestock. Livest. Prod. Sci. 75:257-268.
Cupps, P. T. 1973. Uterine changes associated with impaired fertility in the dairy cow. J. Dairy Sci. 56:878-884.

Dantzer, R., and K. W. Kelley. 2007. Twenty years of research on cytokine-induced sickness behavior. Brain Behav. Immun. 21:153-160.

Davies, C. J., J. R. Hill, J. L. Edwards, F. N. Schrick, P. J. Fisher, J. A. Eldridge, and D. H. Schlafer. 2004. Major histocompatibility antigen expression on the bovine placenta: Its relationship to abnormal pregnancies and retained placenta. Anim. Reprod. Sci. 82-83:267-280.

Demas, G. E., D. L. Drazen, and R. J. Nelson. 2003. Reductions in total body fat decrease humoral immunity. Proc. Biol. Sci. 270:905911

Diskin, M. G., J. J. Murphy, and J. M. Sreenan. 2006. Embryo survival in dairy cows managed under pastoral conditions. Anim. Reprod. Sci. 96:297-311.

Fair, T. 2015. The contribution of the maternal immune system to the establishment of pregnancy in cattle. Front. Immunol. 6:7.

Ferguson, J. D., D. T. Galligan, and N. Thomsen. 1994. Principal descriptors of body condition score in Holstein cows. J. Dairy Sci. 77:2695-2703

Gifford, C. A., B. P. Holland, R. L. Mills, C. L. Maxwell, J. K. Farney, S. J. Terrill, D. L. Step, C. J. Richards, L. O. Burciaga-Robles, and C. R. Krehbiel. 2012. Growth and development symposium: Impacts of inflammation on cattle growth and carcass merit. J. Anim. Sci. 90:1438-1451.

Gomes, G. C., J. E. Zuniga, L. F. Greco, L. D. P. Sinedino, E. S. Ribeiro, N. Martinez, R. S. Bisinotto, F. S. Lima, E. Karakaya, M. A. Engstrom, J. E. P. Santos, and C. R. Staples. 2013. Effects of evaporative cooling prepartum and vitamin E supplementation on performance of Holstein cows during summer in Florida. J. Dairy Sci. 96(Suppl. 1):242. (Abstr.)

Greco, L. F., M. Garcia, R. S. Bisinotto, E. S. Ribeiro, M. G. Favoreto, R. S. Marsola, L. T. Martins, B. Loureiro, F. S. Lima, R. L. A. Cerri, W. W. Thatcher, C. R. Staples, and J. E. P. Santos. 2012. Follicular environment and embryo development of dairy cows fed diet containing low concentration of fatty acids supplemented with different sources of fatty acids. Reprod. Dom. Anim. 47(Suppl. 4):594. (Abstr.)

Hansen, P. J. 2009. Effects of heat stress on mammalian reproduction. Philos. Trans. R. Soc. Lond. B Biol. Sci. 364:3341-3350.

Hernandez, J. A., C. A. Risco, F. S. Lima, and J. E. P. Santos. 2012 Observed and expected combined effects of clinical mastitis and low body condition on pregnancy loss in dairy cows. Theriogenology $77: 115-121$.

International Embryo Transfer Society (IETS). 1998. Manual of the International Embryo Transfer Society. 3rd rev. ed. Int. Embryo Transfer Soc., Savoy, IL.

Krämer, A. J. G., J. P. Jr, and S. Tugendreich. 2014. Causal analysis approaches in Ingenuity Pathway Analysis. Bioinformatics 30:523530

Lavon, Y., G. Leitner, T. Goshen, R. Braw-Tal, S. Jacoby, and D. Wolfenson. 2008. Exposure to endotoxin during estrus alters the timing of ovulation and hormonal concentrations in cows. Theriogenology 70:956-967.

Lima, F. S., R. S. Bisinotto, E. S. Ribeiro, L. F. Greco, H. Ayres, M. G. Favoreto, M. R. Carvalho, K. N. Galvão, and J. E. P. Santos. 2013. Effects of 1 or 2 treatments with prostaglandin $\mathrm{F}_{2 \alpha}$ on subclinical endometritis and fertility in lactating dairy cows inseminated by timed artificial insemination. J. Dairy Sci. 96:6480-6488.

Lima, F. S., L. F. Greco, R. S. Bisinotto, E. S. Ribeiro, N. M. Martinez, W. W. Thatcher, J. E. P. Santos, M. K. Reinhard, and K. N. Galvão. 2015. Effects of intrauterine infusion of Trueperella pyogenes on endometrial mRNA expression of pro-inflammatory cytokines and luteolytic cascade genes and their association with luteal lifespan in dairy cows. Theriogenology http://dx.doi. org/10.1016/j.theriogenology.2015.07.004.

Lima, F. S., A. Vieira-Neto, G. S. F. M. Vasconcellos, R. D. Mingoti, E. Karakaya, E. Solé, R. S. Bisinotto, N. Martinez, C. A. Risco, K. N. Galvão, and J. E. P. Santos. 2014. Efficacy of ampicillin trihydrate or ceftiofur hydrochloride for treatment of metritis and subsequent fertility in dairy cows. J. Dairy Sci. 97:5401-5414. 
Livak, K. J., and T. D. Schmittgen. 2001. Analysis of relative gene expression data using real-time quantitative PCR and the $2-\Delta \Delta \mathrm{Ct}$ method. Methods 25:402-408.

Lussier, J. G., P. Matton, and J. J. Dufour. 1987. Growth rates of follicles in the ovary of the cow. J. Reprod. Fertil. 81:301-307.

McCusker, R. H., and K. W. Kelley. 2013. Immune-neural connections: How the immune system's response to infectious agents influences behavior. J. Exp. Biol. 216:84-98.

Medzhitov, R. 2008. Origin and physiological roles of inflammation. Nature 454:428-435.

Miller, A. N., E. J. Williams, K. Sibley, S. Herath, E. A. Lane, J. Fishwick, D. M. Nash, A. N. Rycroft, H. Dobson, C. E. Bryant, and I. M. Sheldon. 2007. The effects of Arcanobacterium pyogenes on endometrial function in vitro, and on uterine and ovarian function in vivo. Theriogenology 68:972-980.

Monteiro, P. L. J. Jr., E. S. Ribeiro, R. P. Maciel, A. L. G. Dias, E. Solé Jr., F. S. Lima, R. S. Bisinotto, W. W. Thatcher, R. Sartori, and J. E. P. Santos. 2014. Effects of supplemental progesterone after artificial insemination on expression of interferon-stimulated genes and fertility in dairy cows. J. Dairy Sci. 97:4907-4921.

National Animal Health Monitoring System (NAHMS). 2009. Dairy 2007. Part IV: Reference of dairy cattle health and management practices in the United States, 2007. \#N494.0209. Centers for Epidemiology and Animal Health, USDA, Animal and Plant Health Inspection Service, Veterinary Service, Fort Collins, CO.

Oliveira, L. J., S. McClellan, and P. J. Hansen. 2010. Differentiation of the endometrial macrophage during pregnancy in the cow. PLoS ONE 5:e13213.

Ott, T. L., and C. A. Gifford. 2010. Effects of early conceptus signals on circulating immune cells: lessons from domestic ruminants. Am. J. Reprod. Immunol. 64:245-254.

Peter, A. T., W. T. Bosu, and R. J. DeDecker. 1989. Suppression of preovulatory luteinizing hormone surges in heifers after intrauterine infusions of Escherichia coli endotoxin. Am. J. Vet. Res. $50: 368-373$.

Ribeiro, E. S. 2015. Molecular features of reproductive biology associated with fertility in lactating dairy cows. PhD Diss. Department of Animal Sciences, University of Florida, Gainesville.

Ribeiro, E. S., R. S. Bisinotto, F. S. Lima, N. Martinez, L. F. Greco, W. W. Thatcher, and J. E. P. Santos. 2015. Effect of fertility stressors on transcriptome of peripheral blood leukocytes in dairy cows at the onset of conceptus implantation. J. Dairy Sci. 98(Suppl. 2):426.

Ribeiro, E. S., R. G. S. Bruno, A. M. Farias, J. A. Hernández-Rivera, G. C. Gomes, R. Surjus, G. Sasser, D. H. Keisler, W. W. Thatcher T. R. Bilby, and J. E. P. Santos. 2014. Low doses of bovine somatotropin enhance conceptus development and fertility in lactating dairy cows. Biol. Reprod. 90:10-12.

Ribeiro, E. S., K. N. Galvão, W. W. Thatcher, and J. E. P. Santos. 2012. Economic aspects of applying reproductive technologies to dairy herds. Anim. Reprod. 9:370-387.

Ribeiro, E. S., F. S. Lima, L. F. Greco, R. S. Bisinotto, A. P. A. Monteiro, M. Favoreto, H. Ayres, R. S. Marsola, N. Martinez, W. W. Thatcher, and J. E. P. Santos. 2013. Prevalence of periparturient diseases and effects on fertility of seasonally calving grazing dairy cows supplemented with concentrates. J. Dairy Sci. 96:5682-5697.

Rodina, T. M., F. N. T. Cooke, P. J. Hansen, and A. D. Ealy. 2009. Oxygen tension and medium type actions on blastocyst development and interferon-tau secretion in cattle. Anim. Reprod. Sci. $111: 173-188$

Romanyukha, A. A., S. G. Rudneva, and I. A. Sidorov. 2006. Energy cost of infection burden: An approach to understanding the dynamics of host-pathogen interactions. J. Theor. Biol. 241:1-13.

Rutigliano, H. M., F. S. Lima, R. L. A. Cerri, L. F. Greco, J. M. Vilela, V. Magalhães, F. T. Silvestre, W. W. Thatcher, and J. E. P. Santos. 2008. Effects of method of presynchronization and source of selenium on uterine health and reproduction in dairy cows. J. Dairy Sci. 91:3323-3336.

Santos, J. E. P., R. S. Bisinotto, E. S. Ribeiro, F. S. Lima, L. F. Greco, C. R. Staples, and W. W. Thatcher. 2010. Applying nutrition and physiology to improve reproduction in dairy cattle. Soc. Reprod. Fertil. Suppl. 67:387-403.

Santos, J. E. P., H. M. Rutigliano, and M. F. Sá Filho. 2009. Risk factors for resumption of postpartum cyclicity and embryonic survival in lactating dairy cows. Anim. Reprod. Sci. 110:207-221.

Santos, J. E. P., W. W. Thatcher, R. C. Chebel, R. L. A. Cerri, and K. N. Galvão. 2004. The effect of embryonic death rates in cattle on the efficacy of estrus synchronization programs. Anim. Reprod. Sci. 82-83:513-535.

Sheldon, I. M., D. E. Noakes, A. N. Rycroft, D. U. Pfeiffer, and H. Dobson. 2002. Influence of uterine bacterial contamination after parturition on ovarian dominant follicle selection and follicle growth and function in cattle. Reproduction 123:837-845.

Silverstein, R. L., and M. Febbraio. 2009. CD36, a scavenger receptor involved in immunity, metabolism, angiogenesis, and behavior. Sci. Signal. 2:re3.

Smyth, G.K. 2004. Linear models and empirical Bayes methods for assessing differential expression in microarray experiments. Stat. Appl. Genet. Mol. Biol. 3:1-25.

Smyth, G. K. 2005. Limma: Linear models for microarray data. Pages 397-420 in Bioinformatics and Computational Biology Solutions using R and Bioconductor. R. Gentleman, V. Carey, S. Dudoit, R. Irizarry, and W. Huber, ed. Springer, New York, NY.

Thatcher, W. W., P. J. Hansen, T. S. Gross, S. D. Helmer, C. Plante, and F. W. Bazer. 1989. Antiluteolytic effects of bovine trophoblast protein-1. J. Reprod. Fertil. Suppl. 37:91-99.

Vandesompele, J., K. De Preter, F. Pattyn, B. Poppe, N. Van Roy, A. De Paepe, and F. Speleman. 2002. Accurate normalization of real-time quantitative RT-PCR data by geometric averaging of multiple internal control genes. Genome Biol. 3:Research34.

Vieira-Neto, A., R. O. Gilbert, W. R. Butler, J. E. P. Santos, E. S. Ribeiro, M. M. Vercouteren, R. G. Bruno, J. H. Bittar, and K. N. Galvão. 2014. Individual and combined effects of anovulation and cytological endometritis on the reproductive performance of dairy cows. J. Dairy Sci. 97:5415-5425.

Walsh, R. B., J. S. Walton, D. F. Kelton, S. J. LeBlanc, K. E. Leslie, and T. F. Duffield. 2007. The effect of subclinical ketosis in early lactation on reproductive performance of postpartum dairy cows J. Dairy Sci. 90:2788-2796.

Wang, D., M. Garcia, R. S. Bisinotto, N. Martinez, F. S. Lima, L. F. Greco, J. H. Shin, A. M. M. Calaça, A. L. Ranieri, B. L. Artiaga, E. K. Ganda, G. C. Gomes, L. F. V. Becker, S. C. Soares, V. S. Rezende, M. A. Engstrom, J. E. P. Santos, and C. R. Staples. 2013. Effect of supplementing vitamin E and $\beta$-carotene to prepartum Holstein cattle on health and reproductive responses. J. Dairy Sci. 96(Suppl. 1):253 (Abstr.).

Wathes, D. C., Z. Cheng, W. Chowdhury, M. A. Fenwick, R. Fitzpatrick, D. G. Morris, J. Patton, and J. J. Murphy. 2009. Negative energy balance alters global gene expression and immune responses in the uterus of postpartum dairy cows. Physiol. Genomics 39:1-13.

Williams, E. J., K. Sibley, A. N. Miller, E. A. Lane, J. Fishwick, D. M. Nash, S. Herath, G. C. W. England, H. Dobson, and I. M. Sheldon. 2008. The effect of Escherichia coli lipopolysaccharide and tumor necrosis factor alpha on ovarian function. Am. J. Reprod. Immunol. 60:462-473.

Wu, Z., R. A. Irizarry, R. Gentleman, F. Martinez-Murillo, and F. Spencer. 2004. A model-based background adjustment for oligonucleotide expression arrays. J. Am. Stat. Assoc. 99:909-917.

Yuan, J. S., A. Reed, F. Chen, and C. N. Stewart. 2006. Statistical analysis of real-time PCR data. BMC Bioinformatics 7:85. 